Article

\title{
Phase Evolution and Mechanical Behavior of the Semi-Solid SIMA Processed 7075 Aluminum Alloy
}

\author{
Behzad Binesh and Mehrdad Aghaie-Khafri * \\ Faculty of Materials Science and Engineering, K. N. Toosi University of Technology, Tehran 1999143344, Iran; \\ b.binesh@dena.kntu.ac.ir \\ * Correspondence: maghaei@kntu.ac.ir; Tel.: +98-912-308-8389; Fax: +98-21-886-74748
}

Academic Editor: Nong Gao

Received: 12 December 2015; Accepted: 6 February 2016; Published: 23 February 2016

\begin{abstract}
Microstructural and mechanical behaviors of semi-solid 7075 aluminum alloy were investigated during semi-solid processing. The strain induced melt activation (SIMA) process consisted of applying uniaxial compression strain at ambient temperature and subsequent semi-solid treatment at $600-620^{\circ} \mathrm{C}$ for $5-35 \mathrm{~min}$. Microstructures were characterized by scanning electron microscope (SEM), energy dispersive spectroscopy (EDS), and X-ray diffraction (XRD). During the isothermal heating, intermetallic precipitates were gradually dissolved through the phase transformations of $\alpha-\mathrm{Al}+\eta\left(\mathrm{MgZn}_{2}\right) \rightarrow$ liquid phase $(\mathrm{L})$ and then $\alpha-\mathrm{Al}+\mathrm{Al}_{2} \mathrm{CuMg}(\mathrm{S})+\mathrm{Mg}_{2} \mathrm{Si}$ $\rightarrow$ liquid phase (L). However, Fe-rich precipitates appeared mainly as square particles at the grain boundaries at low heating temperatures. $\mathrm{Cu}$ and $\mathrm{Si}$ were enriched at the grain boundaries during the isothermal treatment while a significant depletion of $\mathrm{Mg}$ was also observed at the grain boundaries. The mechanical behavior of different SIMA processed samples in the semi-solid state were investigated by means of hot compression tests. The results indicated that the SIMA processed sample with near equiaxed microstructure exhibits the highest flow resistance during thixoforming which significantly decreases in the case of samples with globular microstructures. This was justified based on the governing deformation mechanisms for different thixoformed microstructures.
\end{abstract}

Keywords: 7075 Al alloy; SIMA; phase transformation; semi-solid; thixoforming

\section{Introduction}

Semi-solid metal processing is a single step fabrication method for production of near net shape metallic parts [1-3]. Advantages of semi-solid processing when it is compared with the conventional casting, forging, and powder metallurgy processes are (i) reduction of the porosity, macrosegregation, and surface cracks; (ii) high dimensional accuracy of the produced parts; (iii) extending of the forming die life due to decreasing of the casting temperature and required forming force; and (iv) the uniform filling of the die and reduction of the manufacturing stages and costs [4,5].

The main goal in the semi-solid forming processes is to achieve a thixotropic microstructure consisting of fine and spherical solid grains which are uniformly distributed in the liquid matrix [6,7]. Various routes have been developed for production of thixotropic aluminum, magnesium, lead, and also ferrous alloys including mechanical and magneto-hydrodynamic (MHD) stirring processes, the thermo-mechanical strain induced melt activation (SIMA) process and the spray casting process [7-9]. The SIMA process which is based on the mechanical work was introduced by Young et al. [10] in the 1980s. This process has received great attention in recent years due to its simplicity, low equipment costs, and its capability to process many engineering alloys [8]. The two main stages of the SIMA process are cold or warm plastic deformation and then partial remelting in the semi-solid range [11,12]. 
Many studies have been focused on the semi-solid microstructure of cast aluminum alloys due to superior semi-solid formability $[12,13]$. However, the cast products show poorer mechanical properties than wrought alloys e.g., 2xxx, 6xxx, and especially 7xxx series. This restricts their applicability in the high strength applications such as aerospace and automotive. On the other hand, control of the semi-solid heat treatment in the wrought alloys is relatively difficult due to their wide solidification range and high sensitivity of solid fraction to temperature variations (steep slope of the solid fraction versus temperature). Furthermore, the wrought alloys are severely susceptible to formation of hot tearing during the forming process [14]. Consequently, investigation on the semi-solid microstructure of wrought aluminum alloys to achieve an appropriate thixotropic microstructure is vital. Yong et al. [15] prepared an appropriate 7075 semi-solid feedstock by 50\% swaging of the specimens at room temperature and then heat treating at $590{ }^{\circ} \mathrm{C}$. They also investigated the properties of the thixoforged part. Multi step heat treatment in thixoforming processes was investigated by Chayong et al. [16,17]. Atkinson et al. [18] studied the recrystallization of $7075 \mathrm{Al}$ alloy during the recrystallization and partial melting (RAP) process. Vaneetveld et al. [19] investigated the effects of heating parameters on the recrystallization in the RAP process and suggested using the high solid fraction to prevent hot tearing in the thixoforging process. Bolouri et al. [20] studied the effect of cold work on the semi-solid microstructure by compression straining of the samples up to $40 \%$ and Mohammadi et al. [21] investigated the effects of the isothermal treatment on the semi-solid microstructure of extruded samples.

Previous studies on the semi-solid processing of 7075 aluminum alloy were mainly restricted to investigations in the field of thixotropic feedstock preparation criteria and producing some thixoformed parts. However, detailed information of the phase transformations during partial remelting and the correlation between the initial microstructure and rheological behavior as well as their final mechanical properties needs to be further investigated. There is a lack of thorough research on this topic in the literature. Consequently, the present work aims to investigate the phase evolution and kinetics of partial remelting during isothermal treatment in the mushy zone and the semi-solid deformation behavior of AA7075 alloy.

\section{Experimental Procedure}

\subsection{Materials and Thermal Analysis}

Commercial extruded round bar of 7075-T6 aluminum alloy was used as the starting material, the chemical composition of which is shown in Table 1.

Table 1. Chemical composition of wrought $7075 \mathrm{Al}$ alloy in wt. \%.

\begin{tabular}{lcccccccc}
\hline Element & Al & Mn & Fe & Cr & Cu & Mg & Zn & Si \\
\hline wt. $\%$ & Bal. & 0.28 & 0.28 & 0.13 & 1.58 & 2.41 & 5.31 & 0.14 \\
\hline
\end{tabular}

In order to determine the solidus and liquidus temperatures and the solid volume fraction versus the temperature curve of 7075 alloy, thermal analysis was carried out using a Metler Star SW 10 differential scanning calorimeter (DSC) apparatus, Metler, Giessen, Germany. Samples of the material (30 mg) were put into the alumina pan and then heated to $700{ }^{\circ} \mathrm{C}$ at $10{ }^{\circ} \mathrm{C} / \mathrm{min}$ under nitrogen atmosphere. The solid volume fraction-temperature relationship was determined using the obtained DSC curve.

\subsection{SIMA Process}

The SIMA process was carried out to obtain a thixotropic microstructure in $7075 \mathrm{Al}$ alloy. Cylindrical samples with a diameter of $30 \mathrm{~mm}$ and height of $35 \mathrm{~mm}$ were machined from the starting material. The samples were stress relieved at $460{ }^{\circ} \mathrm{C}$ for $1 \mathrm{~h}$, and then air cooled. Compression of 
cylindrical samples, with a compression ratio of $20 \%$, was carried out at room temperature using a high strain rate $\left(\sim 15 \mathrm{~s}^{-1}\right)$ hammer apparatus. The compressed specimens were machined to samples with a diameter of $20 \mathrm{~mm}$ and height of $15 \mathrm{~mm}$ to ensure uniform strain in the core section. Isothermal treatment of samples was carried out at three different temperatures of 600,610 , and $620{ }^{\circ} \mathrm{C}$ with an accuracy of $\pm 1{ }^{\circ} \mathrm{C}$ for 5-35 min in a resistance furnace. Heating cycles were interrupted at predetermined interval times and then samples were quenched to study the microstructure.

\subsection{Compression Tests}

The thixoforming process consisting of hot compression experiments at the semi-solid temperature range was carried out on the specimens of different initial microstructures. The cylindrical specimens with $11 \mathrm{~mm}$ in height and $7 \mathrm{~mm}$ in diameter, according to ASTM E209 standard, were prepared from the SIMA processed samples. The isothermal hot compression tests were carried out at temperatures of 600 and $610^{\circ} \mathrm{C}$ and strain rate of $0.3 \mathrm{~s}^{-1}$ using a Gotech-Al7000 model universal testing machine, Gotech, Taichung, Taiwan, equipped with an electrical resistance furnace. The specimens were first preheated to the preset temperature and soaked for $5 \mathrm{~min}$ to homogenize the samples. The specimens were then compressed up to a strain of 0.6 followed by rapid quenching in water. A high accuracy load cell was used to record the true stress values, and the true strain values were computed using the displacement data. A very thin mica plate was used to reduce the friction effect and to prevent the adhesion of the specimen on the die. The specimens were sectioned parallel to the deformation direction to study the microstructural changes.

\subsection{Metallography and Microstructural Characterization}

The microstructure of the quenched samples was examined using the standard metallography method. The surface perpendicular to the direction of the compression was ground with standard SiC abrasive papers and polished with $0.25 \mu \mathrm{m}$ diamond paste. Samples were etched using modified Keller etchant solution ( $3 \mathrm{~mL} \mathrm{HF}, 2 \mathrm{~mL} \mathrm{HCl} ; 20 \mathrm{~mL} \mathrm{HNO}_{3} ; 175 \mathrm{~mL} \mathrm{H}_{2} \mathrm{O}$ ). Microstructural investigations were carried out using a Neophot 32 optical microscope, Norfab, Trondheim, Norway, and Vega@Tescan, Tescan, Libušina, Czech Republic, and Mira3Tescan field emission scanning electron microscope, Tescan, Libušina, Czech Republic, equipped with EDS detector (Tescan, Libušina, Czech Republic). The linear intercept method was used to determine the average grain size. A series of straight lines with a specified length was considered on the optical micrographs for each sample and the average grain size was determined by division of the line length $(L)$ by the number of intercepted grains $(N)$. The shape factor of the solid grains was measured by means of Clemex professional edition image analyzer software (version 5.0, Clemex Technologies Inc., Longueuil, QC, Canada) and using Equation (1) [22]:

$$
F=\frac{\sum_{N=1}^{N} 4 \pi A / P^{2}}{N}
$$

where $A$ and $P$ are area and perimeter of the solid grains, respectively, and $N$ is the number of grains. For each sample, measurements were taken from the whole sectioned area including 300-400 solid particles per sample.

X-ray diffraction (XRD) analysis was used to investigate phase evolution in the semi-solid treated samples. XRD experiment was carried out using a Philips X'pert model apparatus, Panalytical, Eindhoven, The Netherlands, with $\mathrm{CuK} \alpha$ target and wave length of $0.15406 \mathrm{~nm}$.

\section{Results and Discussion}

\subsection{Microstructure and Thermal Analysis of the Starting 7075 Alloy}

Figure 1 shows the scanning electron microscope (SEM) micrographs of the as-received 7075 aluminum alloy. It can be observed (Figure 1a,b) that the microstructure of the alloy consists of directed $\alpha$-Al grains and some precipitate particles in the direction of the initial extrusion process. It is worth 
noting that $\mathrm{Zn}, \mathrm{Cu}$, and $\mathrm{Mg}$ are the main alloying elements in 7075 alloy which play an important role in the formation of precipitates. In the 7xxx series of aluminum alloys, when the $\mathrm{Zn:Mg}$ ratios are between 1:2 and 1:3, $\mathrm{MgZn}_{2}(\eta)$ precipitates are produced at ageing temperatures below $200{ }^{\circ} \mathrm{C}$ and are the main strengthening factor in 7xxx alloys [18]. The dimensions of these precipitates are only a few tens of nanometer which can only be revealed by TEM technique. Considering Figure 1b-d, EDS analysis results of the coarse precipitate particles, as summarized in Table 2, suggested them to be (I) $\mathrm{Al}_{2} \mathrm{CuMg}$ intermetallic phase (which is usually denoted as S-phase) with relatively smooth corners $\left(\mathrm{C}_{1}\right.$ and $\mathrm{C}_{2}$ in Figure $\left.1 \mathrm{~b}, \mathrm{~d}\right),(\mathrm{II}) \mathrm{Al}_{6}(\mathrm{Cu}, \mathrm{Fe})$ intermetallic phase which is also known as $\mathrm{Al}_{23} \mathrm{Fe}_{4} \mathrm{Cu}_{\text {or }}$ $\alpha(\mathrm{FeCu})$ with polygonal $\left(\mathrm{B}_{1}\right.$ in Figure $\left.1 \mathrm{~b}\right)$ or irregular $\left(\mathrm{B}_{2}\right.$ in Figure $\left.1 \mathrm{c}\right)$ shapes, $(\mathrm{III}) \mathrm{Al}_{7} \mathrm{Cu}_{2} \mathrm{Fe}(\beta)$ phase with irregular shapes which have been elongated along the extrusion direction (A in Figure $1 \mathrm{~b}$ ) and (IV) dark $\mathrm{Mg}_{2} \mathrm{Si}$ precipitates with irregular shapes (D in Figure 1c). Considering the EDS analysis results, Fe-rich intermetallic phases $\left(\mathrm{Al}_{6}(\mathrm{Cu}, \mathrm{Fe})\right.$ and $\left.\mathrm{Al}_{7} \mathrm{Cu}_{2} \mathrm{Fe}\right)$ also contain small amounts of manganese which can be substituted for iron as a result of their close atomic radii.
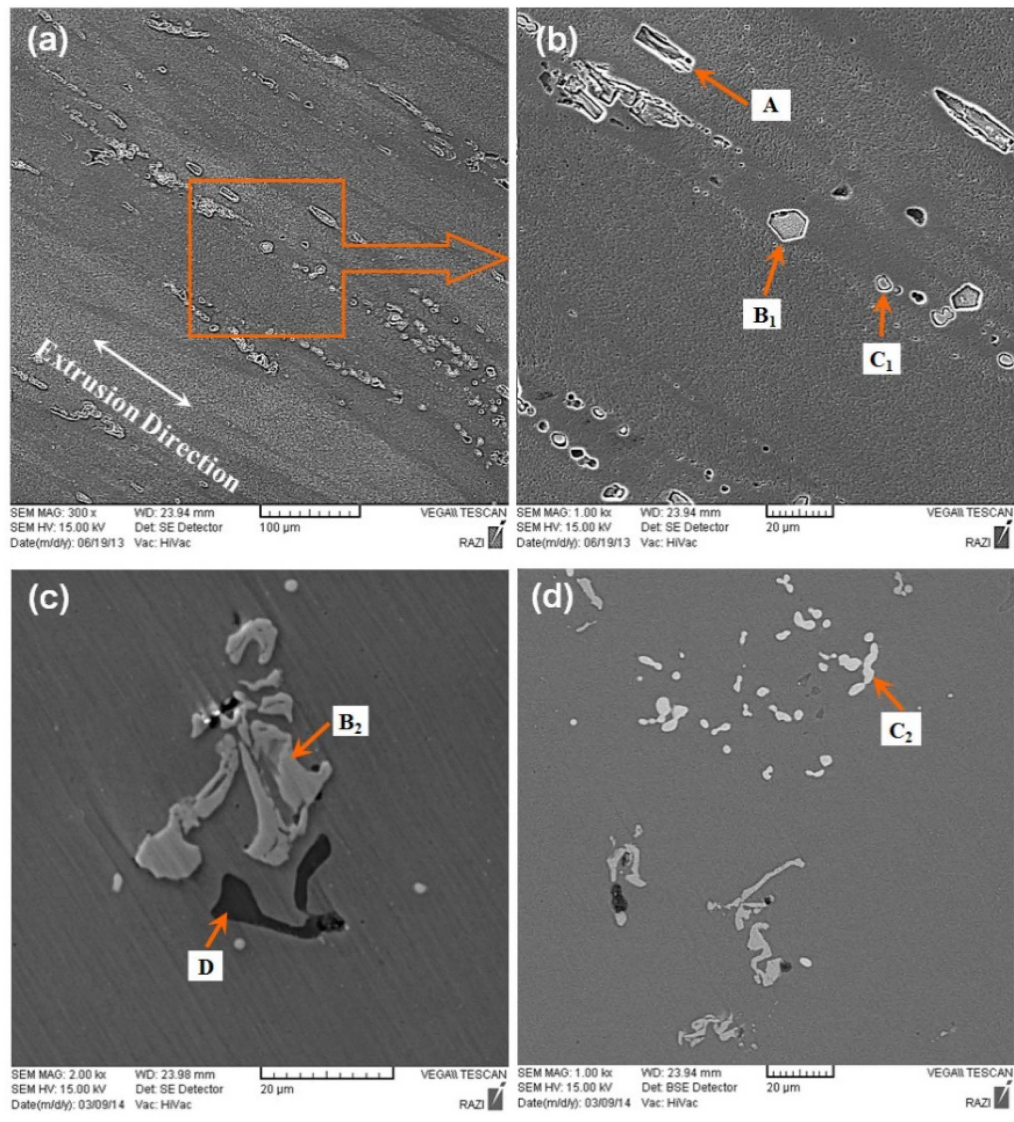

Figure 1. (a) Scanning electron microscope (SEM) secondary electron image; (b) SEM secondary electron image of selected area in (a); (c) SEM secondary electron image; (d) SEM backscattered electron image of as-received 7075 sample.

Figure 2a shows the DSC curve of the 7075 aluminum sample. The solidus and liquidus temperatures based on the DSC curve were 486 and $649^{\circ} \mathrm{C}$, respectively. The characteristic values of the areas under the DSC peaks calculated for mass unity are also included in Figure 2a. The liquid or solid fraction versus the temperature curve was obtained by integration of the DSC curve (Figure 2b). The results were used to determine the isothermal heat treatment temperatures in the SIMA process. It is worth noting that the liquid or solid volume fraction at a known temperature based on Figure $2 \mathrm{~b}$ is not exactly the same as its values appearing in the micrographs. This is due to insufficient cooling rate of the semi-solid samples after isothermal treatment. In other words, some of the liquid fraction 
that transforms to the solid during quenching is considered as solid fraction and therefore the liquid volume fraction observed in the micrographs is always lower than that determined by Figure $2 \mathrm{~b}$.

Table 2. Scanning electron microscope (SEM)/energy dispersive spectroscopy (EDS) analysis results of selected constituent particles highlighted in Figure 1.

\begin{tabular}{|c|c|c|c|c|c|c|}
\hline \multirow{2}{*}{$\begin{array}{l}\text { Content of } \\
\text { Elements }\end{array}$} & \multicolumn{6}{|c|}{ Constituent Particles (at. \%) } \\
\hline & A & $\mathbf{B}_{1}$ & $\mathbf{B}_{2}$ & $\mathrm{C}_{1}$ & $\mathrm{C}_{2}$ & $\mathbf{D}$ \\
\hline $\mathrm{Al}$ & 61.35 & 78.39 & 82.23 & 66.72 & 57.59 & - \\
\hline $\mathrm{Zn}$ & 0.31 & 0.20 & 1.19 & 0.17 & 0.05 & - \\
\hline $\mathrm{Cu}$ & 20.00 & 5.30 & 2.67 & 17.16 & 18.64 & - \\
\hline $\mathrm{Mg}$ & 0.03 & 0.02 & 0.81 & 13.83 & 23.38 & 69.42 \\
\hline $\mathrm{Fe}$ & 13.71 & 11.61 & 10.64 & 0.52 & 0.02 & - \\
\hline $\mathrm{Si}$ & 1.79 & 0.13 & 1.09 & 0.47 & 0.03 & 30.58 \\
\hline $\mathrm{Mn}$ & 2.27 & 3.56 & 1.33 & 0.52 & 0.18 & - \\
\hline $\mathrm{Cr}$ & 0.55 & 0.79 & 0.04 & 0.59 & 0.10 & - \\
\hline Phase shape & Irregular & polygonal & Irregular & Spherical & $\begin{array}{l}\text { Irregular with } \\
\text { round corners }\end{array}$ & Dark-Irregular \\
\hline $\begin{array}{l}\text { Closest } \\
\text { phase }\end{array}$ & $\mathrm{Al}_{7} \mathrm{Cu}_{2} \mathrm{Fe}$ & $\mathrm{Al}_{6}(\mathrm{Cu}, \mathrm{Fe})$ & $\mathrm{Al}_{6}(\mathrm{Cu}, \mathrm{Fe})$ & $\mathrm{Al}_{2} \mathrm{CuMg}$ & $\mathrm{Al}_{2} \mathrm{CuMg}$ & $\mathrm{Mg}_{2} \mathrm{Si}$ \\
\hline
\end{tabular}
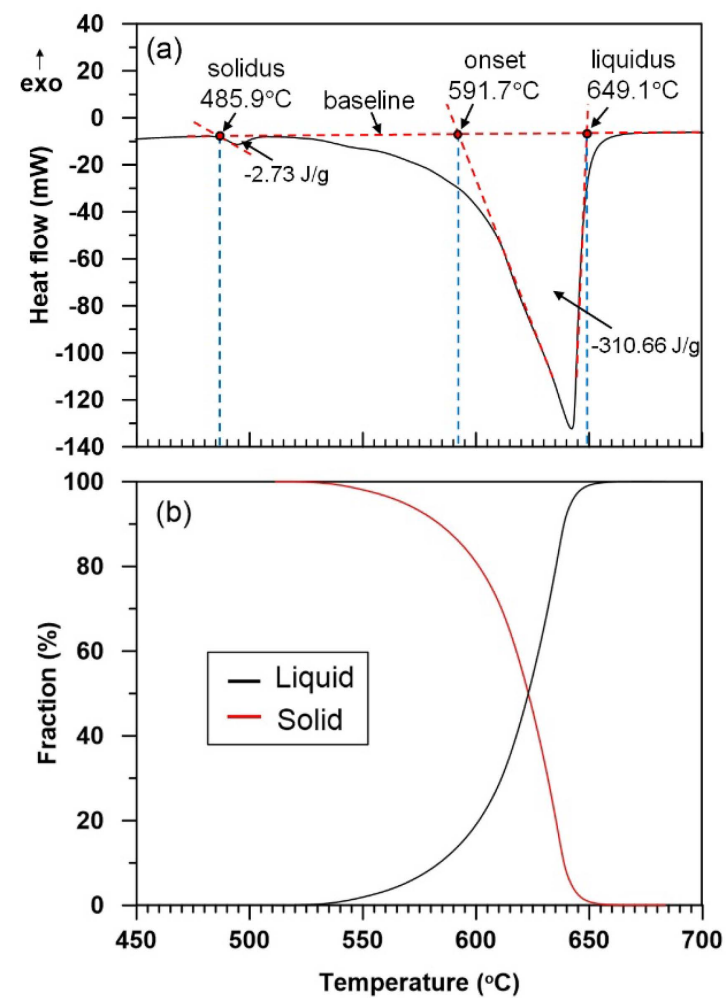

Figure 2. (a) Differential scanning calorimeter (DSC) curve of $7075 \mathrm{Al}$ alloy at a heating rate of $10^{\circ} \mathrm{C} / \mathrm{min}$; (b) solid and liquid volume fraction versus temperature derived from the DSC curve.

\subsection{Microstructural Evolution during Partial Remelting of the Compressed 7075 Alloy}

Microstructures of 7075 specimens after 20\% compression and isothermal heat treating at the semi-solid temperature of $600{ }^{\circ} \mathrm{C}$ for various times during the SIMA process are shown in Figure 3 . The initial microstructure consisted of plastically deformed grains that gradually transforms to a globular microstructure of spherical and equiaxed grains after heating and partial remelting at $600{ }^{\circ} \mathrm{C}$. 
Micrographs of Figure 3a,b show that following 5 min heating of the sample at $600{ }^{\circ} \mathrm{C}$, no evidence of recrystallization was observed. Following the increase of the heating time up to 10 min, a near equiaxed microstructure consisting of elongated and polygonal solid grains with what appears to be quenched liquid at the grain boundaries was formed (Figures $3 c$ and $4 a$ ). In some zones, the size of these grains is quite small which implies a recrystallization phenomenon. Moreover, the formation of the liquid phase is expected to be as a result of partial remelting during isothermal holding at $600{ }^{\circ} \mathrm{C}$. The results of research conducted by Atkinson et al. [18] revealed that liquids are first formed at the recrystallized grain boundaries of RAP processed 7075 alloy because these are areas with higher solute concentrations. However, the liquid phase has not penetrated thoroughly into the grain boundaries which results in incomplete grain boundary wetting, as shown in Figure 4a. The mechanism of low melting point phase formation in the semi-solid microstructure is extensively discussed in Section 3.4. With further extension of the heating time up to $15 \mathrm{~min}$, the whole microstructure was transformed into individual polygonal grains due to separation and increase of the liquid phase (Figure 3d). The grain size significantly increased compared with that of the grains which had just recrystallized and separated, shown in Figure 3c. This indicates that the separation and coarsening were in competition.
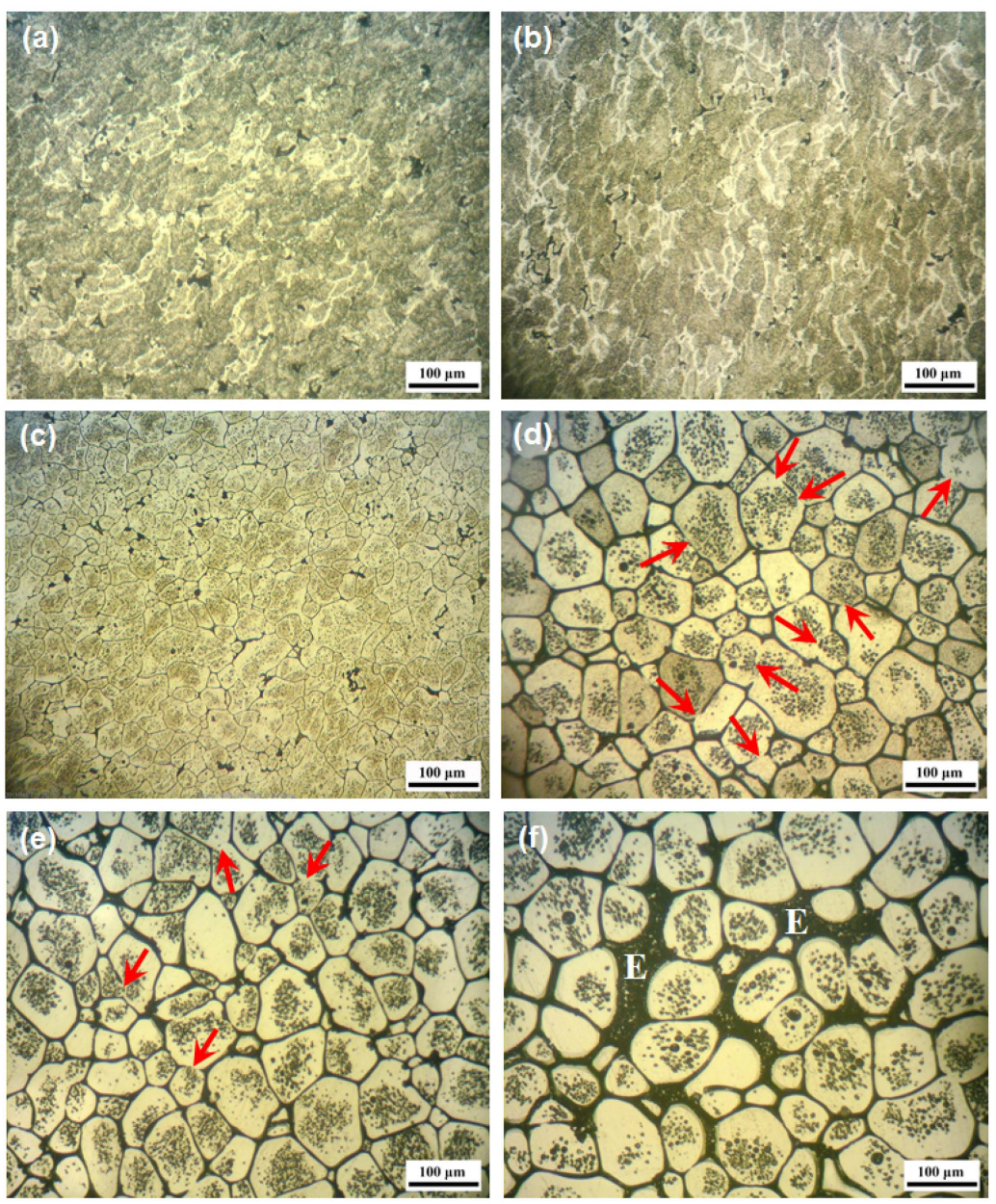

Figure 3. Optical micrographs of samples compressed $20 \%$ and isothermally heat treated at $600{ }^{\circ} \mathrm{C}$ for (a) $0 \mathrm{~min}$; (b) $5 \mathrm{~min}$; (c) $10 \mathrm{~min}$; (d) $15 \mathrm{~min}$; (e) $25 \mathrm{~min}$; (f) $35 \mathrm{~min}$. 

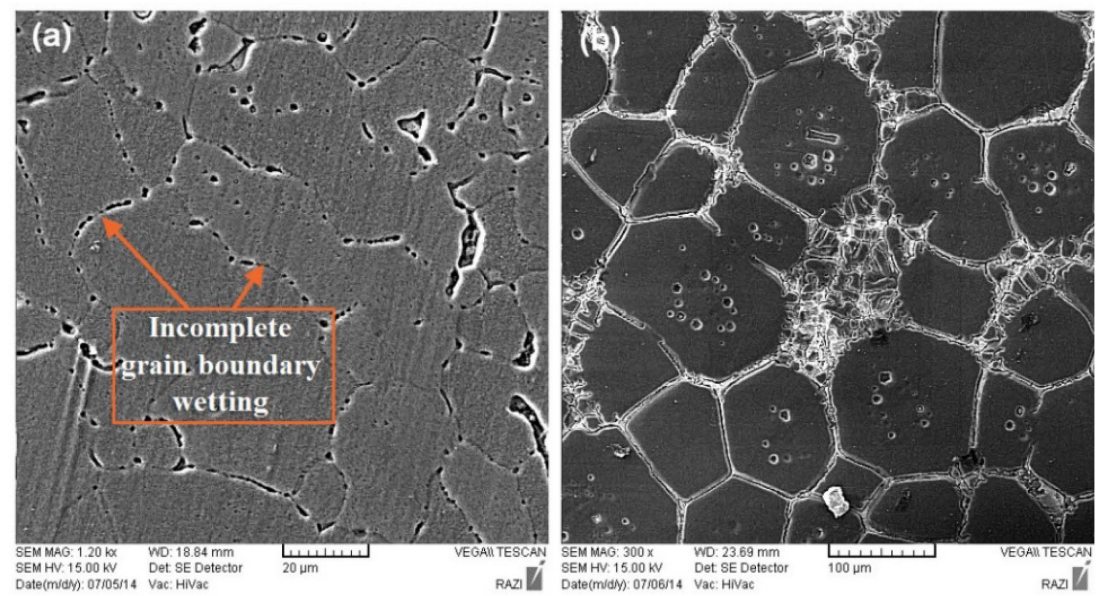

Figure 4. SEM images of $20 \%$ compressed 7075 alloy heat treated at $600{ }^{\circ} \mathrm{C}$ for (a) $10 \mathrm{~min}$; (b) $35 \mathrm{~min}$.

Comparing the primary grain size of the deformed sample and the resulting polygonal particle size, it can be suggested that the recrystallization and separation dominated during the period of $5 \mathrm{~min}$ to $10 \mathrm{~min}$ or at a longer time and then the coarsening became the dominant process. During the coarsening stage, it was found that the liquid amount is relatively small and the neighboring grains are only separated by a thin liquid layer (Figure 3c,d).

During the isothermal heating period of $15 \mathrm{~min}$ to $25 \mathrm{~min}$, the interconnection between the solid grains reduced and the grains gradually became spherical (Figure 3e). The spheroidization mainly occurred during this stage. During the period of $25 \mathrm{~min}$ to $35 \mathrm{~min}$, the liquid phase obviously increased (comparing Figure $3 \mathrm{e}, \mathrm{f}$ ) which finally led to intergranular formation of thick eutectic regions following 35 min heating of the sample (indicated by the E letter in Figure 3f). This is evidenced with the eutectic phase becoming the predominant feature at grain boundaries after semi-solid soaking (Figure $4 \mathrm{~b}$ ). It can be expected that the coarsening of spherical grains will occur with raising of the heating time over $35 \mathrm{~min}$.

In addition, some intragranular islands which are claimed to be liquid pools just before quenching, were observed within the solid grains. Therefore, the semi-solid microstructure consisted of $\alpha$-Al spherical solid grains, intergranular eutectic liquid film and entrapped liquid droplets within the solid grains. Entrapped liquid droplets were produced in two different ways. The first was as a consequence of alloying elements segregation within the solid particles during the partial remelting. In this case, some fine liquid droplets entrap within the solid grains. The second one was due to coalescence of solid grains with complex geometrical shape during the heating stage to decrease the solid-liquid phase interfacial energy. In this condition, larger droplets of the liquid phase, in comparison with the former, were created within the grains [23]. As is observed in Figure 3, with longer holding times some of the fine liquid droplets as a result of coalescence phenomena or atomic diffusion joined to the larger liquid droplets. Subsequently, these new liquid droplets become more spherical to reduce the solid/liquid interfacial energy. Finally, with further increase of the holding time, a lesser number of the entrapped liquid droplets was produced owing to diffusion into the liquid phase matrix that surrounded the solid grains.

\subsection{Kinetics of the Microstructural Evolution during Partial Remelting}

Considering the obtained results in the present study, the kinetics of the microstructural evolution of 7075 samples during the SIMA process can be divided into four steps. (I) recovery, recrystallization and structural separation, (II) coarsening of polygonal solid grains, (III) spheroidization of polygonal solid grains and (IV) coarsening of spherical grains. Recovery, recrystallization, and structural separation mainly occur in the early stages of the isothermal heating operation. During recovery and recrystallization, vacancies are joined to each other and dislocations are rearranged as low energy 
structures by climbing or cross slipping and subgrain boundaries are created. In this step, grains of high dislocation density are replaced by new subgrains with less dislocation density. Moreover, because the holding temperature is higher than the eutectic line, partial remelting also occurred [20,23]. It has been found that when the angle between subgrains is greater than $20^{\circ}$, the surface energy of the grain boundaries is greater than two fold of the solid/liquid interfacial energy $\left(\gamma_{\mathrm{gb}}>2 \gamma_{\mathrm{sl}}\right)$. If these grain boundaries contact with liquid phase, the grain boundaries are replaced by a thin liquid film. Considering the vice versa case i.e. $\gamma_{\mathrm{gb}}<2 \gamma_{\mathrm{sl}}$, low energy grain boundaries will be formed which are not wetted by the liquid phase. If two solid grains reach together through such a low energy boundary, they can be joined together and stimulate the coalescence of solid particles [24].

With rising of the isothermal heating time, the liquid volume fraction becomes greater and isolated polygonal solid grains are created. By continuing the heating process, these grains grow and coarsen. The growth and coarsening of the solid grains in the SIMA process are controlled by two mechanisms of coalescence and Ostwald ripening. During the growing and coarsening of the microstructure, diffusion of the solid material from regions with high curvature to low curvature points occurs based on Equation (2) [12]. This subsequently provides the required driving force for spheroidization of solid grains.

$$
\Delta T_{r}=-\frac{2 \sigma T_{m} V_{s} k}{\Delta H}
$$

where $\Delta T_{\mathrm{r}}=T_{\mathrm{m}}-T$ represents the difference to the equilibrium melting point, $T_{\mathrm{m}}$ is the equilibrium transformation temperature, $k$ is the mean surface curvature of the solid particles, $\sigma$ is the surface tension and $\Delta H$ (a negative value) is the molar change in the enthalpies of the solid and liquid.

As long as the grains are not spherical during semi-solid treatment, the spheroidization process leads to change of the particles shape from polygonal to spherical where the numbers per unit volume remain constant. Following this stage, smaller grains which have a lower melting point according to Equation (2), are melted in favor of the larger grains and the numbers per unit volume are reduced. The microstructure of samples that have been subjected to partial remelting in the SIMA process, are evolved by one of the mentioned mechanisms depending on the sphericity of solid grains and the amount of the liquid volume fraction [25].

Ostwald ripening is a diffusion controlled mechanism and acts as the dominant mechanism at high liquid volume fractions i.e. high heating temperatures and long holding times. This mechanism is less effective in particle growth but has a great influence on the spheroidization of solid grains. In contrast, the coalescence mechanism which needs shorter holding times and a small amount of liquid fractions, is more effective in grain growth and has a minor effect on the spheroidization process [25-27].

When the liquid fraction is low (early stages of heating operation), the solid grains are readily in contact with one another, and coalescence is the dominant mechanism in the coarsening of the microstructure. This can be verified by considering the microscopic images shown in Figure $3 \mathrm{~d}-\mathrm{f}$. The arrows on the micrographs show that some grain boundaries are removed due to coalescence of the solid grains. Therefore, it can be concluded that the growing and coarsening of grains in the sample heated at $600{ }^{\circ} \mathrm{C}$ for $15 \mathrm{~min}$ mainly occurs through the coalescence mechanism due to the relatively low liquid fraction (Figure 3d). With further increase of the holding time (Figure 3e,f), the liquid fraction increased and Ostwald ripening mechanism was more effective in the coarsening process. When the majority of the solid grains gained uniform surface curvature through these two mechanisms, the growth of spherical grains commences. Therefore, spheroidization and further growth of solid grains by the two mentioned competing mechanisms are expected in the SIMA process [25].

\subsection{Phase Evolution and Alloying Element Distribution during Partial Remelting of Compressed 7075 Alloy}

A close examination of the micrographs in Figure 3 reveals that the volume fractions of precipitates in the microstructure reduce with the rise of the isothermal holding time. This is clearly confirmed by increasing the brightness of the recrystallized solid grains. XRD results shown in Figure 5 also confirm 
this phenomenon. The X-ray diffraction pattern of the $20 \%$ compressed sample prior to the isothermal treatment, indicated that the microstructure consists of $\alpha-\mathrm{Al}$ phase and $\eta, \mathrm{S}, \mathrm{Al}_{6}(\mathrm{Cu}, \mathrm{Fe}), \mathrm{Al}_{7} \mathrm{Cu}_{2} \mathrm{Fe}$, and $\mathrm{Mg}_{2} \mathrm{Si}$ intermetallic phases, which is similar to the as-received sample (Figure 1). According to the X-ray diffraction patterns of samples heat treated at $600{ }^{\circ} \mathrm{C}$ for 5 to $35 \mathrm{~min}$, it is clear that the intensity of $\eta, S$, and $\mathrm{Mg}_{2} \mathrm{Si}$ peaks decrease with the increase of the holding time. The diffraction peaks of the $20 \%$ compressed sample are shown by symbols and the corresponding peaks in each case are specified by arrows for the other samples in Figure 5. The diffraction peaks of $\eta, S$, and $\mathrm{Mg}_{2} \mathrm{Si}$ phases almost disappeared after heating for $25 \mathrm{~min}$. However, some diffraction peaks of Fe-rich intermetallic phases $\left(\mathrm{Al}_{7} \mathrm{Cu}_{2} \mathrm{Fe}\right.$ and $\left.\mathrm{Al}_{6}(\mathrm{Cu}, \mathrm{Fe})\right)$ show little change with prolonging of the holding time. Considering the sample heated for $35 \mathrm{~min}$, the presence of $\mathrm{Al}_{7} \mathrm{Cu}_{2} \mathrm{Fe}$ and $\mathrm{Al}_{6}(\mathrm{Cu}, \mathrm{Fe})$ phases was distinguishable. However, no evidence of $\eta, \mathrm{S}$, and $\mathrm{Mg}_{2} \mathrm{Si}$ phases was observed. This illustrates that Fe-rich secondary particles cannot be dissolved into the matrix for the semi-solid treatment conditions used in the present study.

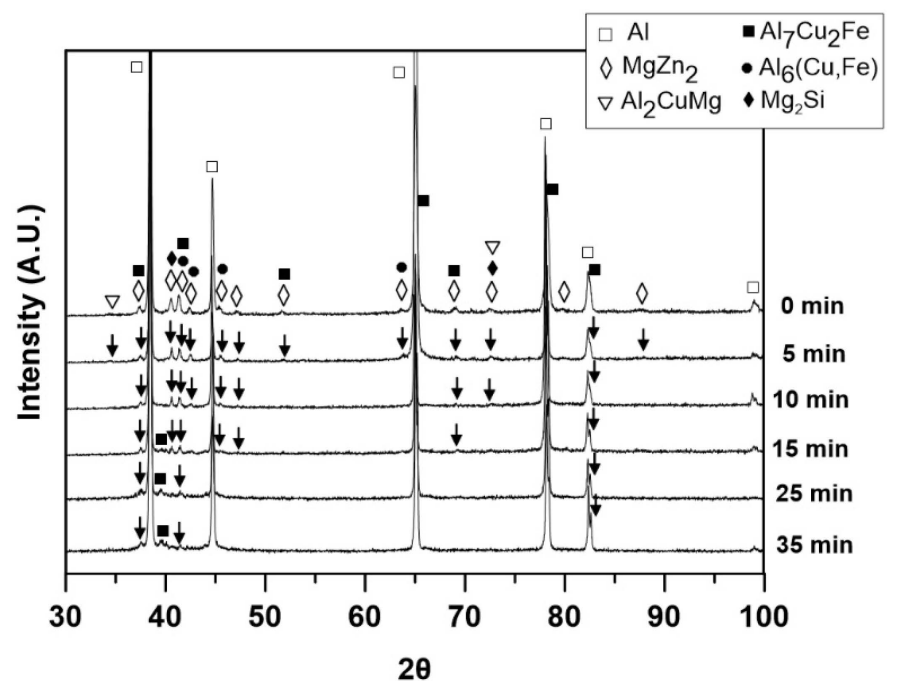

Figure 5. X-ray diffraction (XRD) patterns of $20 \%$ compressed 7075 alloys, heat treated at $600{ }^{\circ} \mathrm{C}$ for different times and then water quenched.

Previous work reported that the melting temperature of $\eta$-phase in $7 x x x$ alloys is $475-480{ }^{\circ} \mathrm{C}[26,27]$. This is fairly well correlated with the first peak in the DSC curve of the starting material with an enthalpy of $2.7 \mathrm{~J} / \mathrm{g}$ in Figure 1. The solution temperatures of $\mathrm{S}$ and $\mathrm{Mg}_{2} \mathrm{Si}$ phases are $490-501{ }^{\circ} \mathrm{C}$ [28,29] and $478-525^{\circ} \mathrm{C}$ [30], respectively, depending on the $\mathrm{Mg}$ content of the alloy. Considering the XRD results (Figure 5) and solution temperature of intermetallic precipitates, it can be suggested that the dissolving of intermetallic particles commences with melting of $\eta$ precipitates after heating for 10 min through the reaction of $\alpha-\mathrm{Al}+\eta \rightarrow \mathrm{L}$. Following the increase of the heating time, dissolving of $S$ and $\mathrm{Mg}_{2} \mathrm{Si}$ intermetallic particles also occurs through the phase transformation of $\alpha-\mathrm{Al}+\mathrm{S}+\mathrm{Mg}_{2} \mathrm{Si} \rightarrow \mathrm{L}$. These precipitates are fully dissolved after isothermal heating for $25 \mathrm{~min}$.

The Fe-rich intermetallic precipitates have higher solution temperatures and are usually stable over $600{ }^{\circ} \mathrm{C}$ [31]. Microstructural observations revealed that the Fe-rich intermetallic particles, shown in Figure 6, precipitate at grain boundaries during partial remelting. Precipitation of these particles at the grain boundaries has a great influence on pinning of the grain boundaries movement. Therefore, it may cause the retardation of the particle growth and coarsening during the isothermal treatment. This is discussed in more detail in Section 3.5. 

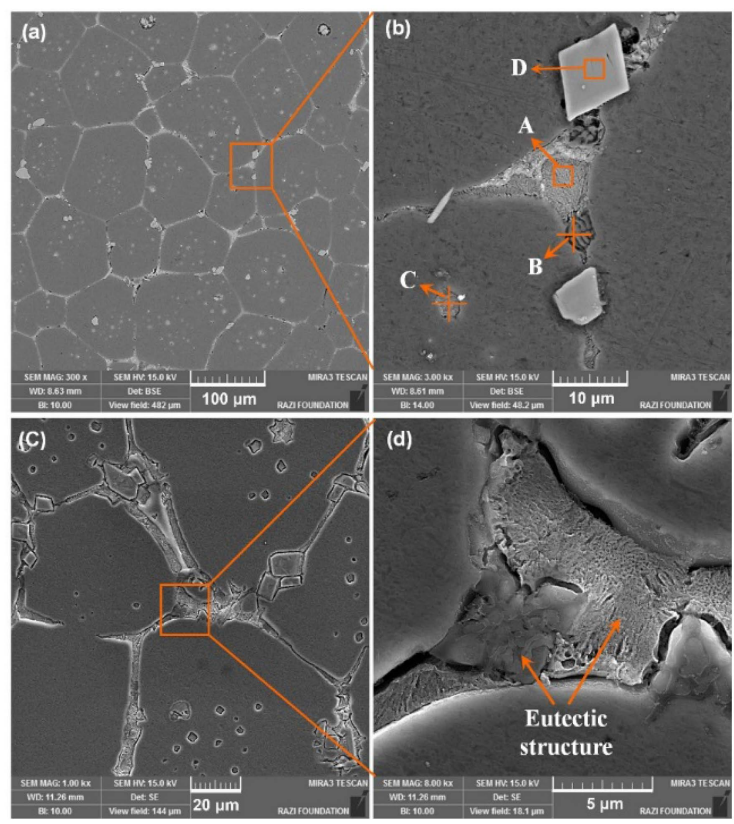

Figure 6. SEM electron images of the strained samples heat treated at (a) $600{ }^{\circ} \mathrm{C}$ for $25 \mathrm{~min}$; (b) $600{ }^{\circ} \mathrm{C}$ for $25 \mathrm{~min}$ in higher magnification; (c) $610^{\circ} \mathrm{C}$ for $25 \mathrm{~min}$; (d) $610^{\circ} \mathrm{C}$ for $25 \mathrm{~min}$ in higher magnification.

It can be concluded from the above discussion that the distribution of alloying elements in the microstructure is significantly changed during the isothermal treatment and solution of the constituent particles. Segregation and distribution of the alloying elements has a great influence on the microstructural evolution during semi-solid treatment. Moreover, this affects the mechanical properties of the subsequent thixoformed parts [32-34]. Figure 6 shows the SEM images of the compressed samples heat treated at $600{ }^{\circ} \mathrm{C}$ (Figure $6 \mathrm{a}, \mathrm{b}$ ) and $610^{\circ} \mathrm{C}$ (Figure $6 \mathrm{c}, \mathrm{d}$ ) for $25 \mathrm{~min}$. The EDS analysis results of the marked areas (A to D) in Figure $6 \mathrm{~b}$ are shown in Figure 7. Intense concentration of $\mathrm{Cu}$ at the grain boundaries (point $\mathrm{A}$ ) was observed. In addition, Si intensely segregated at other regions of the grain boundaries (point B). The entrapped liquid droplets within the solid grains (point $\mathrm{C}$ ) also showed high concentration of $\mathrm{Cu}$. Although the segregation of $\mathrm{Cu}$ at the grain boundaries and within the liquid droplets has been reported in the literature [35,36], the segregation of $\mathrm{Si}$ is an unreported phenomenon in the semi-solid microstructure of $7075 \mathrm{Al}$ alloy. Solid grains are depleted from $\mathrm{Cu}$ as a consequence of the segregation of $\mathrm{Cu}$ at the grain boundaries. This results in a rise in the solidus temperature in these regions and a decline of the temperature at the grain boundaries. Finally, chemical composition approaches Al-Cu eutectic composition which facilitates grain boundary melting. The segregation of $\mathrm{Si}$ at other regions of the grain boundaries derives grain boundary chemistry closer to Al-Si eutectic composition. Therefore, it can be concluded that the formation of low melting phases at grain boundaries is mainly influenced by the high content of $\mathrm{Cu}$ and $\mathrm{Si}$.

Grain boundary regions with low solidus temperature remelt during the isothermal heating. Thus, a eutectic liquid film surrounds the solid grains. Melting of solid grains occurs on further increasing the heating temperature. However, it should be noted that the segregation of $\mathrm{Cu}$ and $\mathrm{Si}$ at the grain boundaries improves on raising the heating temperature due to more intense atomic diffusion. The EDS analysis of the precipitate particles at the grain boundaries (point D) in Figure 6 (Figure 7d) demonstrates Fe-rich intermetallic phases. This is also confirmed by XRD patterns in Figure 5. As discussed earlier, these particles cannot be dissolved at $600^{\circ} \mathrm{C}$ and appear mainly as square particles at the grain boundaries in the semi-solid microstructure. The results of the microstructural investigations in this research showed that the amount of these particles reduce on increasing the isothermal heating temperature to $620^{\circ} \mathrm{C}$ and isothermal heating for longer times (>15 min). 

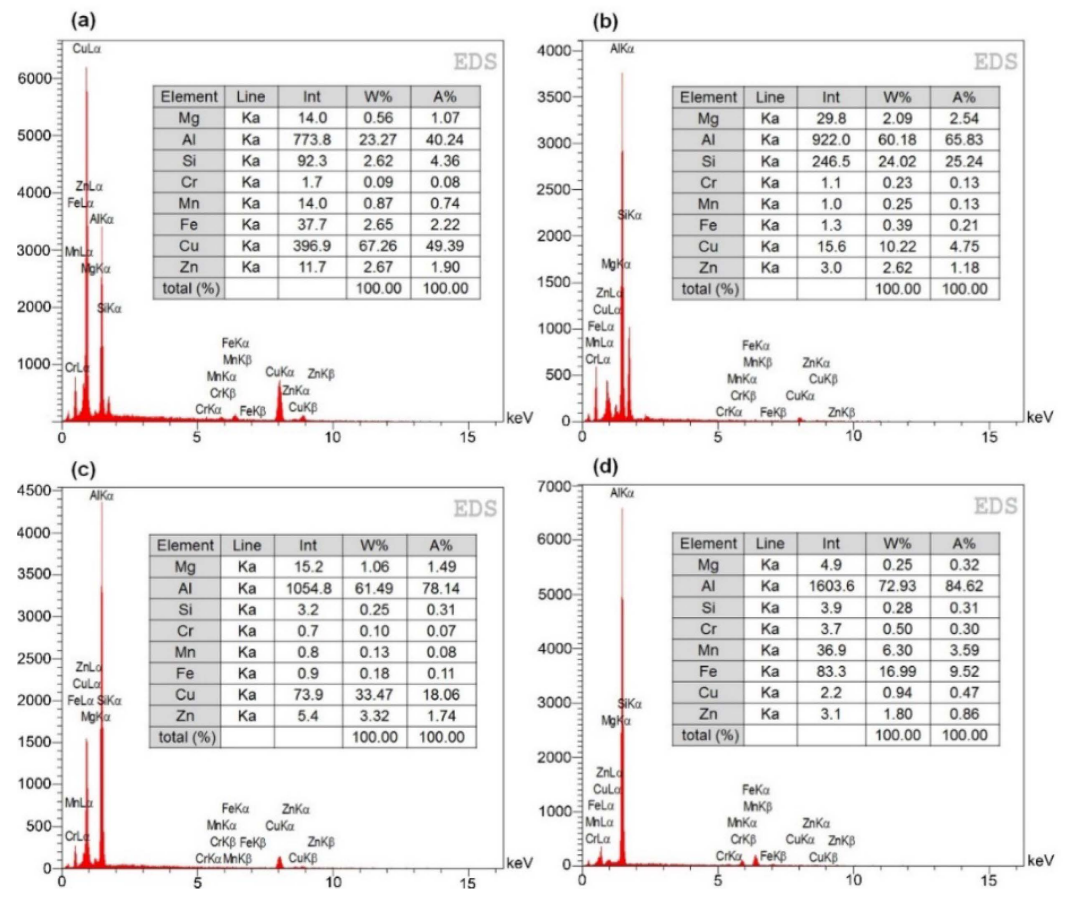

Figure 7. SEM/EDS analysis of various points in Figure 6: (a) A; (b) B; (c) C; (d) D.

Figure 8 shows the EDS mapping of the main alloying elements of the strained samples heat treated at $600{ }^{\circ} \mathrm{C}$ for $25 \mathrm{~min}$. Considerable segregation of $\mathrm{Cu}$ and $\mathrm{Si}$ at the grain boundaries was also confirmed by the EDS mapping analysis of $\mathrm{Cu}$ and $\mathrm{Si}$ (Figure 8c,d). In addition, an appreciable depletion of $\mathrm{Mg}$ was observed at the grain boundaries (Figure 8e). However, as it can be observed from the EDS analysis results in Figure 7 and the EDS mapping of Mg in Figure 8e, the Al-Si eutectics have a higher content of $\mathrm{Mg}$ compared with the $\mathrm{Al}-\mathrm{Cu}$ eutectics. There was no appreciable change in $\mathrm{Zn}$ content at various point of the microstructure (Figure $8 \mathrm{f}$ ). This is in contrast to the result of researches conducted by Bolouri et al. [35] and Shim et al. [37] who reported the segregation of $\mathrm{Zn}$ at the grain boundaries of a SIMA processed 7075 alloy and semi-solid Al-Zn-Mg alloy prepared by the cooling plate method, respectively. Atkinson et al. [18] also indicated that $\mathrm{Zn}$ and $\mathrm{Mg}$ are enriched at the grain boundaries of RAP processed 7075 alloy. Moreover, as it can be observed in Figure 8g,h, the grain boundary precipitates contain a high amount of Fe and Mn. As the EDS analysis revealed (Figure 7c,d), these precipitates are attributed to Fe-rich intermetallic particles. An overview of the alloying elements distribution in the semi-solid microstructure of $7075 \mathrm{Al}$ alloy can be observed in Figure 8i.

Figure 9a-e shows SEM images of compressed samples heat treated at $600{ }^{\circ} \mathrm{C}$ for $5-35 \mathrm{~min}$. Variations of the main alloying elements of 7075 alloy (i.e. $\mathrm{Cu}, \mathrm{Zn}$, and $\mathrm{Mg}$ ) at the grain boundaries and grain centers in these samples are also demonstrated in Figure 9f. The EDS analysis results of the grain centers and grain boundaries (Figure 9f), showed that the $\mathrm{Cu}$ concentration reduces within the solid grains on increasing the isothermal holding time at $600^{\circ} \mathrm{C}$. In other words, $\mathrm{Cu}$ segregation rises at grain boundaries with increasing holding time. $\mathrm{Mg}$ concentration declined at the grain boundaries on raising the holding time and no significant change was observed in $\mathrm{Zn}$ concentration at various parts of the microstructure.

Considering that (i) $\mathrm{Zn}, \mathrm{Mg}, \mathrm{Si}$, and $\mathrm{Cu}$-bearing intermetallic precipitates ( $\eta, \mathrm{S}$ and $\mathrm{Mg}_{2} \mathrm{Si}$ ) are dissolved gradually on prolonging the holding time according to XRD patterns of the SIMA processed samples (Figure 5), (ii) $\mathrm{Zn}$ and $\mathrm{Mg}$ have higher solubility in $\mathrm{Al}$ compared with $\mathrm{Cu}$ and $\mathrm{Si}$ according to the Al-Zn, Al-Mg, Al-Cu and Al-Si binary phase diagrams [38], and (iii) no distinct peak for these elements appeared in the XRD patterns (Figure 5), it can be concluded that $\mathrm{Zn}$ and Mg elements are easily dissolved in $\alpha-\mathrm{Al}$, while $\mathrm{Cu}$ and $\mathrm{Si}$ significantly segregate at the grain boundaries. Since, 
$\mathrm{Zn}$ has a smaller atomic radius relative to aluminum $(0.133 \mathrm{~nm}$ compare to $0.143 \mathrm{~nm})$ [39], it can be concluded that dissolving $\mathrm{Zn}$ in the aluminum crystal lattice leads to reduction of the lattice parameter of aluminum. However, dissolving $\mathrm{Mg}$ in $\mathrm{Al}$, as a result of its greater atomic radius, can result in increase of the lattice parameter of aluminum. The shifting of the Al main peaks in XRD patterns (Figure 5) to higher angles, as shown in Figure 10a for (111) reflection of the aluminum matrix, revealed that the lattice parameter of Al decreases on prolonging the heating time (Figure 10b) based on Bragg's equation $(n \lambda=2 d \sin \theta)$. It seems that dissolving $\mathrm{Zn}$ in $\mathrm{Al}$ is more effective than $\mathrm{Mg}$. This may be as a result of the higher $\mathrm{Zn}$ content of 7075 alloy. According to Figure 10b, the lattice parameter is gently reduced with prolonging holding time to $15 \mathrm{~min}$ and then with further extension of the holding time to $25 \mathrm{~min}$, the lattice parameter precipitously declines. Finally, further increasing of the heating time results in a gentle reduction of the lattice parameter. These observations clearly correlate with the XRD results in Figure 5. According to the XRD patterns, great amounts of $\eta$ precipitates dissolve during the isothermal heating of the sample for $25 \mathrm{~min}$. This results in dissolving of a higher amount of $\mathrm{Zn}$ atoms in the aluminum lattice and therefore leads to a significant decline of the lattice parameter.
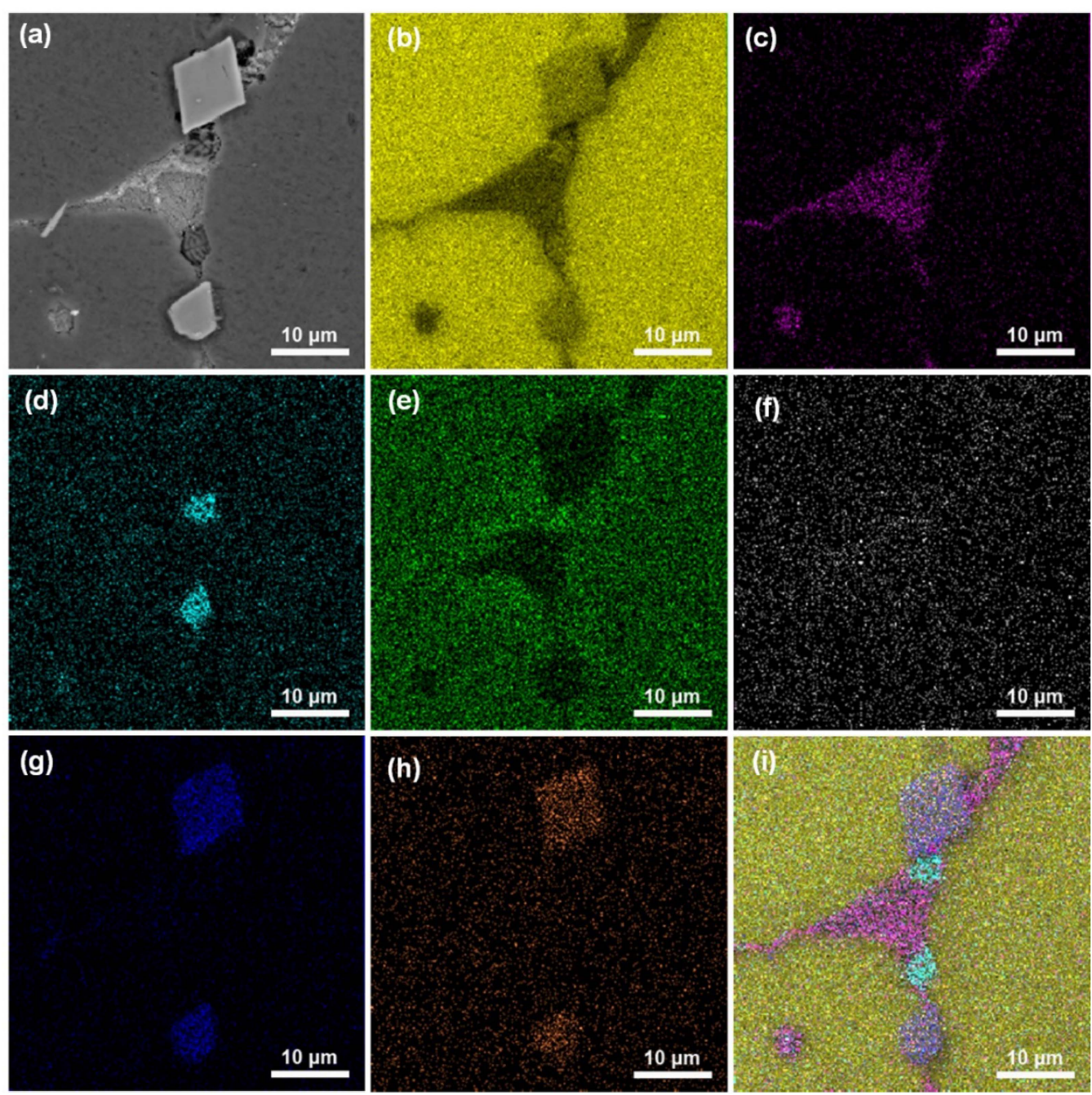

Figure 8. (a) SEM image; (b) Al; (c) Cu; (d) Si; (e) Mg; (f) Zn; (g) Fe; (h) Mn; (i) Al Fe Si Mn Cu X-ray image analysis of a compressed sample isothermally heat treated at $600{ }^{\circ} \mathrm{C}$ for $25 \mathrm{~min}$. 

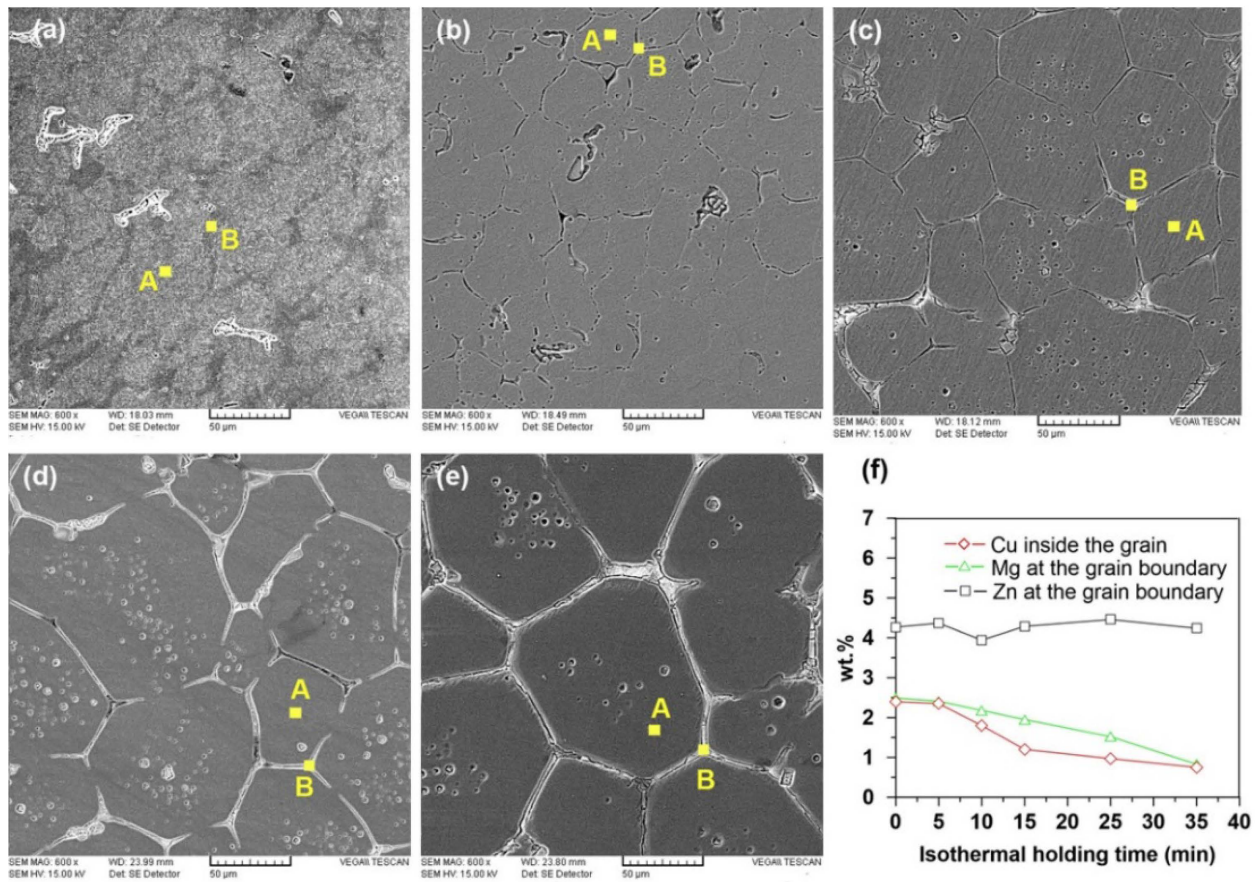

Figure 9. SEM images of sample compressed $20 \%$, heat treated at $600{ }^{\circ} \mathrm{C}$ for (a) $5 \mathrm{~min}$; (b) $10 \mathrm{~min}$; (c) $15 \mathrm{~min}$; (d) $25 \mathrm{~min}$; (e) $35 \mathrm{~min}$ and then water quenched; (f) EDS analysis results of the grain centers (A point) and grain boundaries (B point).

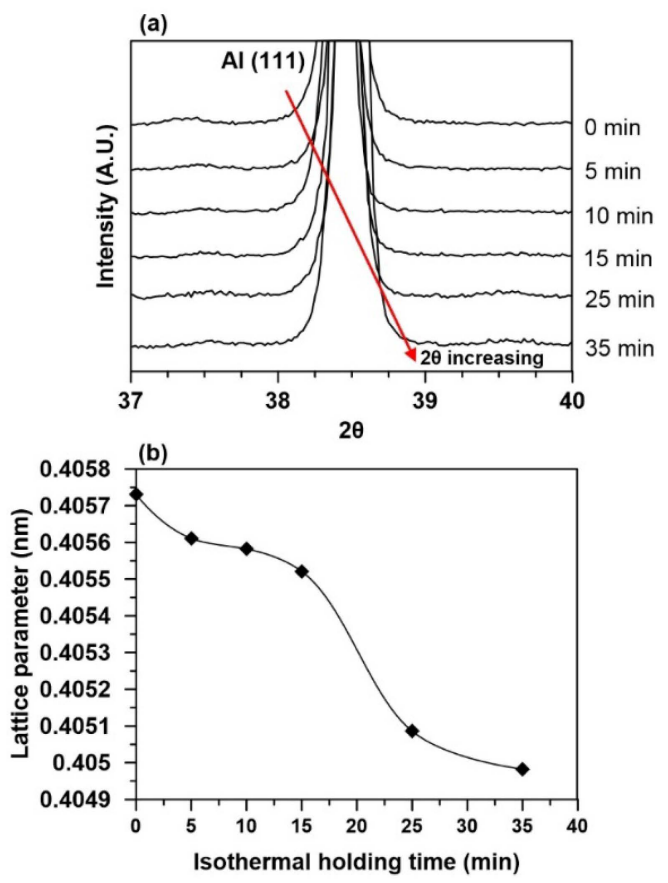

Figure 10. (a) XRD peaks corresponding to the $\mathrm{Al}(111)$ plane in XRD patterns of Figure 5; (b) lattice parameter variations of aluminum in $20 \%$ compressed samples heated at $600{ }^{\circ} \mathrm{C}$ for different times.

\subsection{Effects of Isothermal Holding Temperature and Time on the Semi-Solid Microstructure}

Figure 11 shows the quenched microstructures of 7075 samples which compressed $20 \%$ and heated at 600,610 , and $620^{\circ} \mathrm{C}$ for different times. A close examination of the micrographs in Figure 11 reveals 
that the liquid fraction and the sphericity of solid grains become greater on raising the isothermal holding temperature and time. Another fact that can be observed in the micrographs is the reduction of the number of entrapped liquid droplets within the grains and increase of their size on extending the heating temperature and time.
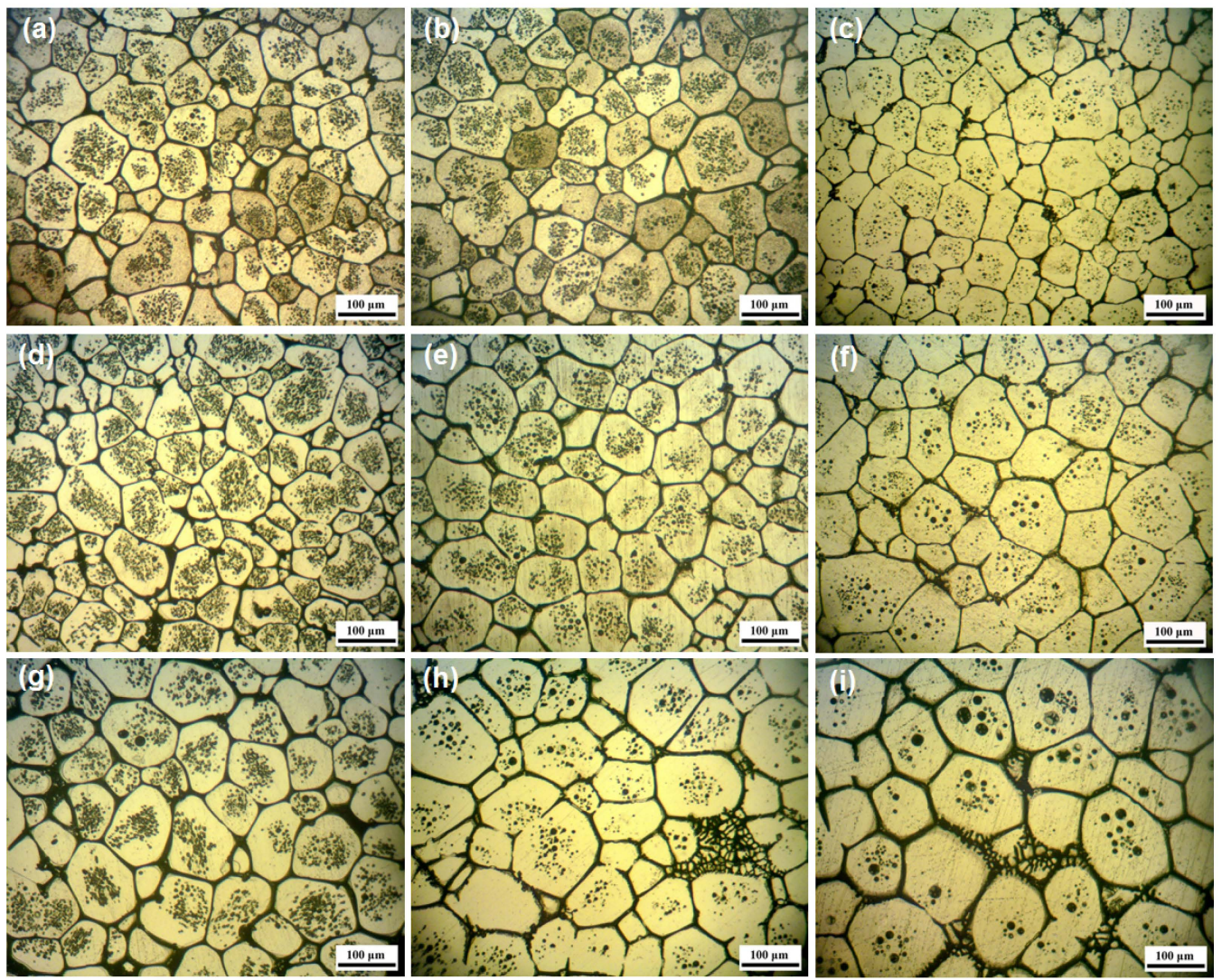

Figure 11. Optical micrographs of 7075 samples with $20 \%$ compression ratio heat treated at (a) $600{ }^{\circ} \mathrm{C} / 15 \mathrm{~min}$; (b) $610{ }^{\circ} \mathrm{C} / 15 \mathrm{~min}$; (c) $620{ }^{\circ} \mathrm{C} / 15 \mathrm{~min}$; (d) $600{ }^{\circ} \mathrm{C} / 25 \mathrm{~min}$; (e) $610{ }^{\circ} \mathrm{C} / 25 \mathrm{~min}$; (f) $620^{\circ} \mathrm{C} / 25 \mathrm{~min}$; (g) $600{ }^{\circ} \mathrm{C} / 35 \mathrm{~min}$; (h) $610^{\circ} \mathrm{C} / 35 \mathrm{~min}$; (i) $620^{\circ} \mathrm{C} / 35 \mathrm{~min}$.

Variations of the average grain size and shape factor of strained samples heated at different temperatures and times are shown in Figure 12. As expected, the average grain size and shape factor become greater with increase of the holding temperature and time. However, it is worth noting that no significant variation of the average grain size of samples heated for $15 \mathrm{~min}$ on raising the holding temperatures from 600 to $620^{\circ} \mathrm{C}$ is observed. Disintegration of solid particles owing to liquid phase penetration between the solid grains occurred during the primary heating time. This is due to the fact that a large number of solid grains with the same crystallographic orientations make contact with each other. It seems that the mechanism of particle disintegration is in equilibrium with the coalescence mechanism at longer heating times up to $15 \mathrm{~min}$. Therefore, the solid grain sizes show no appreciable variation. In contrast, with further extension of holding times at various heating temperatures, the liquid film thickness between the solid grains and the liquid fraction becomes greater. Consequently, the Ostwald ripening mechanism can be considered as a dominant mechanism in the solid grain coarsening process. Figure $3 e$, $f$ shows separated spherical grains with large entrapped liquid droplets which is a fact that supports the discussion above. 

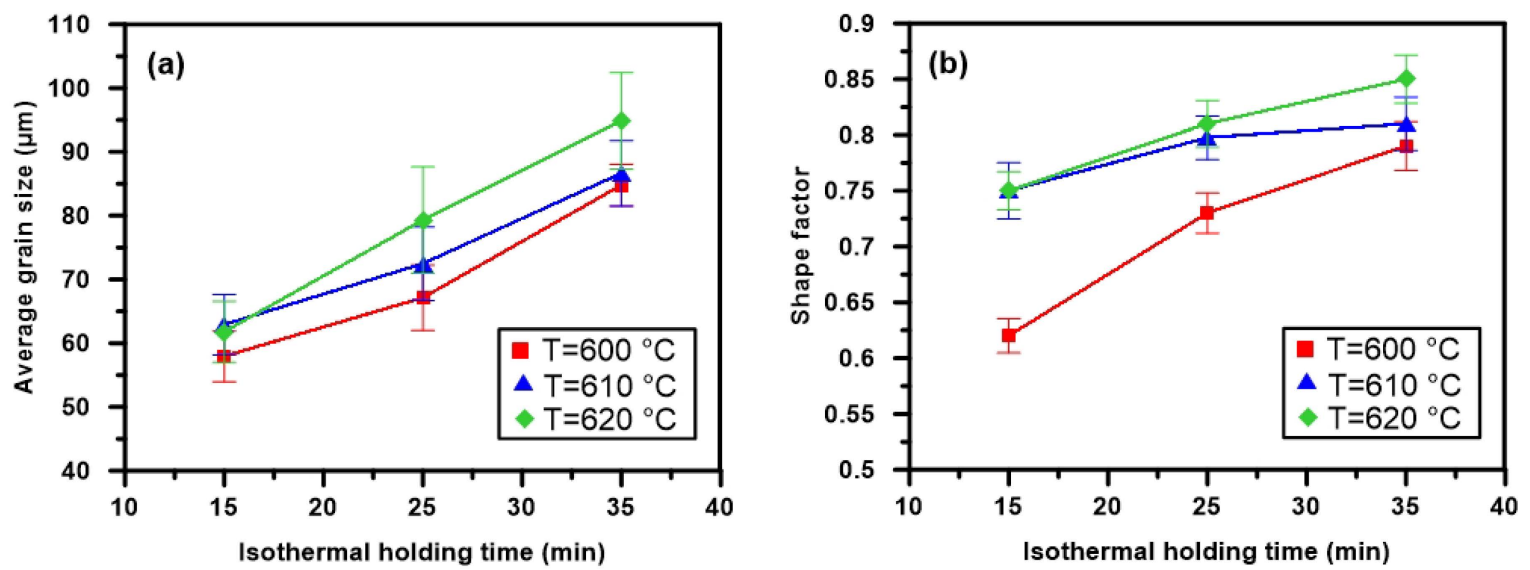

Figure 12. Variations of (a) the average grain size; (b) shape factor versus isothermal holding time of compressed samples heated at 600,610 , and $620^{\circ} \mathrm{C}$.

Results of research conducted by Vaneetveld et al. [40] showed that the semi-solid feedstock with high solid fraction $\left(f_{\mathrm{s}} \approx 0.84\right)$ shows better thixotropic behavior during semi-solid forming and also significantly prevents the formation of some defects such as porosity and shrinkage during the forming process. According to the solid fraction versus temperature curve in Figure $2 b$, the solid fraction is relatively low at $620^{\circ} \mathrm{C}\left(f_{\mathrm{s}} \approx 0.55\right)$. Thus, heating samples at such a temperature leads to undesirable coarsening of the solid grains. In addition, the solid fraction is more sensitive to temperature variations at $620{ }^{\circ} \mathrm{C}$, when compared to the lower temperatures in which control of the semi-solid forming parameters is difficult. Consequently, the semi-solid microstructure obtained by isothermal heating at $620^{\circ} \mathrm{C}$ is inappropriate for thixotropic applications. However, high solid fractions were observed following heating at temperatures of 600 and $610^{\circ} \mathrm{C}$. The solid volume fractions at 600 and $610^{\circ} \mathrm{C}$ were 0.8 and 0.7 , respectively (Figure $2 \mathrm{~b}$ ). Average grain size smaller than $75 \mu \mathrm{m}$ and shape factor greater than 0.7 were obtained for strained samples heated at 600 and $610{ }^{\circ} \mathrm{C}$ for $25 \mathrm{~min}$. Therefore, the isothermal heating temperature range of 600 to $610^{\circ} \mathrm{C}$ and holding time of $25 \mathrm{~min}$ can be considered the optimum semi-solid treatment condition.

The coarsening kinetics can be expressed by the Lifshitz-Slyozov-Wagner (LSW) relationship [41,42]:

$$
D^{n}-D_{0}^{n}=k t
$$

where $D$ and $D_{0}$ are the final and initial grain sizes, respectively, $t$ is the isothermal holding time, $k$ is the coarsening rate constant and $n$ is the power exponent. It has been found that $n$ is 3 for volume diffusion controlled systems in the semi-solid state [12].

In the present research, the coarsening rate constant $(k)$ was calculated by fitting a power relationship to the experimental results. Figure 13 shows the cube of grain size variations versus isothermal holding time for compressed samples heated at 600,610 , and $620^{\circ} \mathrm{C}$, where $D_{0}$ is the average grain size when the holding time is $15 \mathrm{~min}$. The regression coefficients of the fitted equations are close to 1 . Thus, it can be concluded that the coarsening kinetics of solid particles during the isothermal heating of deformed 7075 samples at the semi-solid temperature range are fairly well correlated with the LSW equation. The values of the coarsening rate constant $k$ for the samples are summarized in Table 3. The main characteristics of the variation of $k$ values when the temperature was decreased from 620 to $600{ }^{\circ} \mathrm{C}$ are as follows; (i) the $k$ value significantly reduced on decreasing the temperature from 620 to $610^{\circ} \mathrm{C}$; (ii) this was followed by a slight increase at $600{ }^{\circ} \mathrm{C}$. 


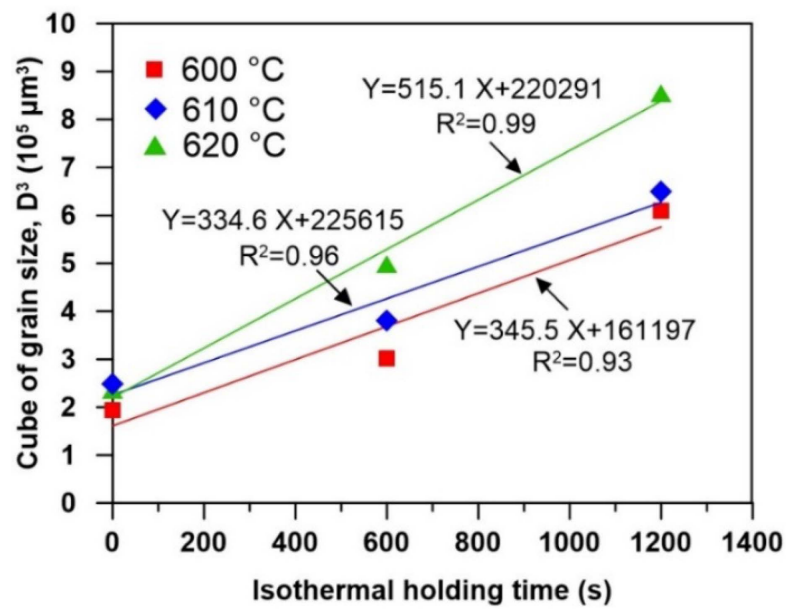

Figure 13. Variations of the cube of average globule size versus isothermal holding time of compressed samples at heating temperatures of $600-620^{\circ} \mathrm{C}$ where $R^{2}$ is the regression coefficient.

Table 3. Values of coarsening rate constants of compressed samples at various isothermal holding temperatures.

\begin{tabular}{cccc}
\hline \multirow{2}{*}{ Compression ratio (\%) } & \multicolumn{3}{c}{ Coarsening rate constant, $k\left(\mu \mathbf{m}^{\mathbf{3}} \cdot \mathbf{s}^{-1}\right)$} \\
\cline { 2 - 4 } & $\mathbf{6 0 0}{ }^{\circ} \mathbf{C}$ & $\mathbf{6 1 0}^{\circ} \mathbf{C}$ & $\mathbf{6 2 0}^{\circ} \mathbf{C}$ \\
\hline 20 & 345 & 334 & 515 \\
\hline
\end{tabular}

According to the Doherty theorem [32], the coarsening rate accelerates with rising solid fraction $\left(f_{\mathrm{s}}\right)$ for $f_{\mathrm{s}}$ higher than 0.6. However, the research conducted by Manson-Whitton et al. [41] showed opposite results for higher solid fractions $\left(f_{\mathrm{s}} \geqslant 0.7\right)$ in the case of spray formed $\mathrm{Al}-4 \% \mathrm{Cu}$. Therefore, they proposed a modified model considering the solid-solid contacts effect during coarsening and a transition solid fraction $\left(f_{\mathrm{s}} \approx 0.7\right)$. For the solid fractions greater than the transition value, the $k$ value decreased with an increase in the solid fraction. However, for the solid fraction lower than the transition value, the $k$ value increased on increasing the solid fraction. Considering the holding temperatures that correspond to the calculated solid fractions (Figure 2b), for solid fractions greater than 0.7 (at $610^{\circ} \mathrm{C}$ ) and the transition value of 0.8 (at $600{ }^{\circ} \mathrm{C}$ ), the coarsening process of solid grains is similar to the model proposed by Manson-Whitton et al. [41]. On the other hand, an unexpected increase in $k$ values is observed for solid fractions lower than 0.7 . This can be attributed to (i) further increase of the atomic diffusion and more effective Ostwald ripening mechanism and (ii) a less retarding effect of the precipitate particles (Fe-rich intermetallic particles) for a holding temperature up to $620^{\circ} \mathrm{C}$. These particles bring about convoluting grain boundaries as is marked by arrows in Figure 14, suggesting pinning and retardation of the grain boundary liquid film migration during the solid grains coarsening. The effect of the presence of intermetallic precipitates at the grain boundaries on the coarsening rate of aluminum alloys has also been reported by Manson-Whitton et al. [41] and de Freitas et al. [43]. The results obtained in the present research indicate that Fe-rich precipitates mainly dissolve or become smaller than the thickness of the liquid film on raising the heating temperature up to $620^{\circ} \mathrm{C}$. Thus, the movement of grain boundaries can easily occur and leads to greater values of the coarsening rate constant. 

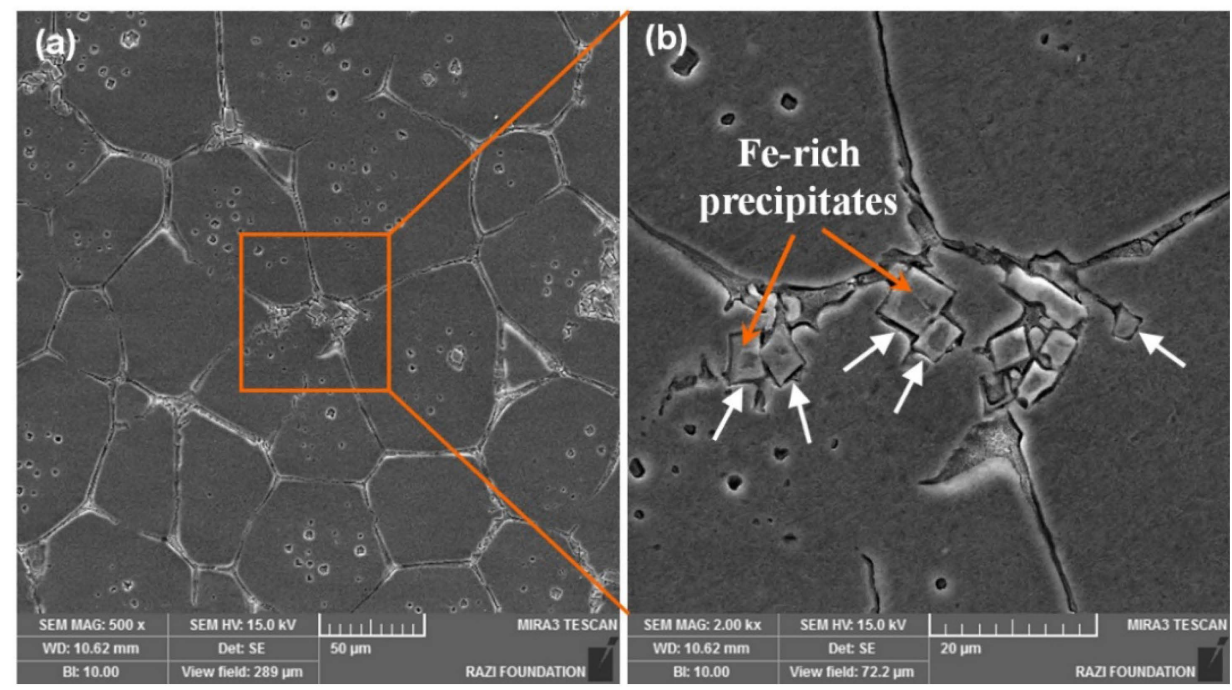

Figure 14. (a) SEM image of a strained sample heat treated at $600{ }^{\circ} \mathrm{C}$ for $15 \mathrm{~min}$; (b) SEM image of selected area in (a).

\subsection{Semi-Solid Deformation Behavior}

Figure 15 shows a typical load-displacement curve obtained from the hot compression experiment. As it can be observed, the load rises to a maximum $\left(L_{\max }\right)$ and then decreases to a minimum value $\left(L_{\text {min }}\right)$. The thixotropic flow behavior consisted of a transient regime and a steady state regime, as shown in Figure 15. Semi-solid alloys with an equiaxed microstructure are considered as deformable semi-cohesive granular solids saturated with liquid [44]. The solid grains are partially interconnected by unwetted grain boundaries and liquid fills the interstitial spaces. Large deformation results in the destruction of some solid grain boundary bonds to allow grains to move freely and rearrange through sliding and rolling. The cohesion at the grain level reflects the strength of unwetted grain boundaries and results in a flow resistance. With further deformation breakdown the solid agglomerates, the load (stress) decreases to a steady state level.

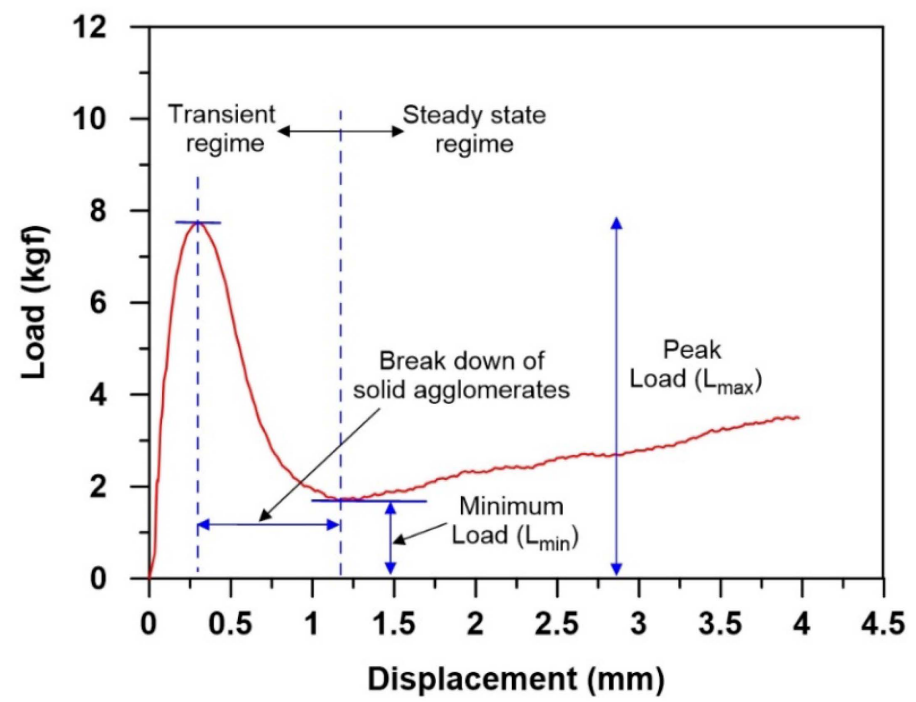

Figure 15. Typical load versus displacement curve of the hot compressed semi-solid 7075 sample (isothermally treated at $600{ }^{\circ} \mathrm{C}$ for $15 \mathrm{~min}$ ) at $600{ }^{\circ} \mathrm{C}$. 
Tzimas and Zavaliangos [44] suggested that the flow resistance of semi-solid alloys at high solid volume fraction is controlled by four mechanisms: (i) elastoplastic deformation at grain contacts, (ii) destruction of cohesive bonds between solid grains, (iii) resistance to the flow of liquid relative to the solid, and (iv) resistance to grain rearrangement. Mechanism (i) is dominant in the rising part of the flow curve and mechanism (ii) results in the breakdown of solid particles and a significant drop in the load value. Mechanisms (iii) and (iv) are dominant in the second stage, and their relative contribution to the overall resistance to flow depends on the volume fraction of solid.

The stress-strain curves obtained from the SIMA processed 7075 samples with different initial microstructures after hot compression at $600{ }^{\circ} \mathrm{C}$ (for the SIMA samples isothermally treated at $600{ }^{\circ} \mathrm{C}$ for $10-35 \mathrm{~min}$ ) and $610{ }^{\circ} \mathrm{C}$ (for the SIMA sample isothermally treated at $610^{\circ} \mathrm{C}$ for $15 \mathrm{~min}$ ) are shown in Figure 16. The stress exhibits a maximum value at a relatively low strain in all samples. The strain at the peak stress varies between 0.01 and 0.04 . The peak stress then drops to a steady state value, typically at a strain of $0.1-0.18$. The stress at the steady state shows no significant change with strain. Figure 17 shows the variation of the peak and steady state stresses for the SIMA processed samples with different initial microstructures. As is evident from Figures 16 and 17 the sample semi-solid treated at $600{ }^{\circ} \mathrm{C}$ for $10 \mathrm{~min}$ exhibits the highest peak and steady state stresses. On increasing the isothermal holding time to $25 \mathrm{~min}$ at $600{ }^{\circ} \mathrm{C}$, which results in a coarser and more spherical solid grains in the initial microstructure (see Figure 12), both the peak and steady state stresses decreased significantly. The peak stress showed a slight increase while a considerable increase in the steady state stress was observed with further increase of the holding time to $35 \mathrm{~min}$ in the SIMA process. Moreover, the increase of the deformation temperature had a great influence on the stress-strain curve and resulted in a decrease of thixotropic strength, as is observed for the sample semi-solid treated at $610{ }^{\circ} \mathrm{C}$ for $15 \mathrm{~min}$.

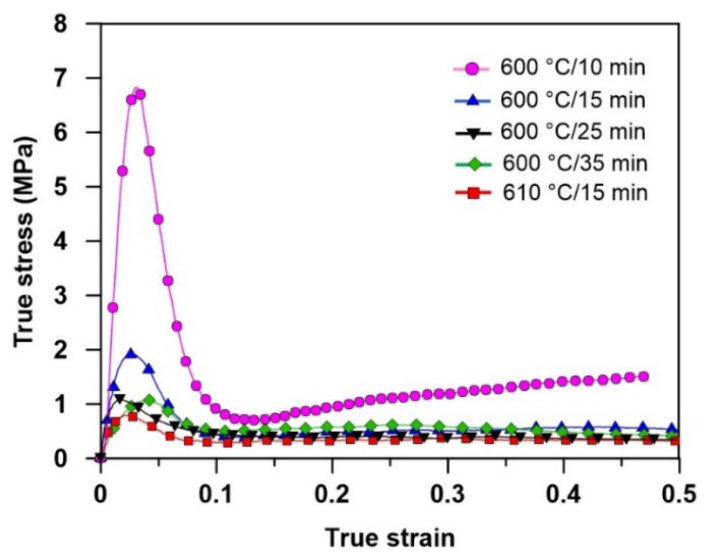

Figure 16. Stress-strain curves of strain induced melt activation (SIMA) processed samples with different initial microstructures.

The descending trend of the thixotropic strength (decreasing of the peak stress) with increase of the isothermal holding time in the SIMA process can be attributed to the geometry of the solid grains. As was previously described, the deformation of samples with equiaxed microstructure mainly occurs by grain rearrangement through sliding and rolling. However, the microstructures consisting of non-equiaxed and elongated grains are deformed by plastic deformation due to which the relative movement among solid grains is constrained. Figure 18 shows the hot compressed microstructure of SIMA processed samples with near equiaxed and globular initial microstructure. The microstructure of various regions ( 1 to 3 in Figure 18a) of the hot compressed SIMA sample processed at $600{ }^{\circ} \mathrm{C}$ for 10 min (see Figure 3c) revealed that this sample cannot be deformed by grain rearrangement due to the significant geometric interference of the solid grains which results in plastic deformation of the grains (Figure $18 b-d)$. As is observed in Figure $18 b-d$, the solid grains are severely deformed and elongated 
in the direction of compression which results in a textured microstructure. This leads to a much higher resistance to flow compared to samples with a completely spheroidized microstructure. On prolonging the isothermal heating time, the sphericity of solid grains increases and the interconnection decreases (Figure 3) which results in easier movement and sliding during deformation and reduction of flow resistance. The high flow stress of the SIMA sample heated for $35 \mathrm{~min}$ can be ascribed to the coarsened initial microstructure with an average grain size of $85 \mu \mathrm{m}$. According to Clarke [45], an increase in the particle size leads to an increase in the apparent viscosity of the semi-solid slurry. Therefore, a sample with coarsened initial microstructure possesses a more viscous flow and requires higher loads for thixoforming.

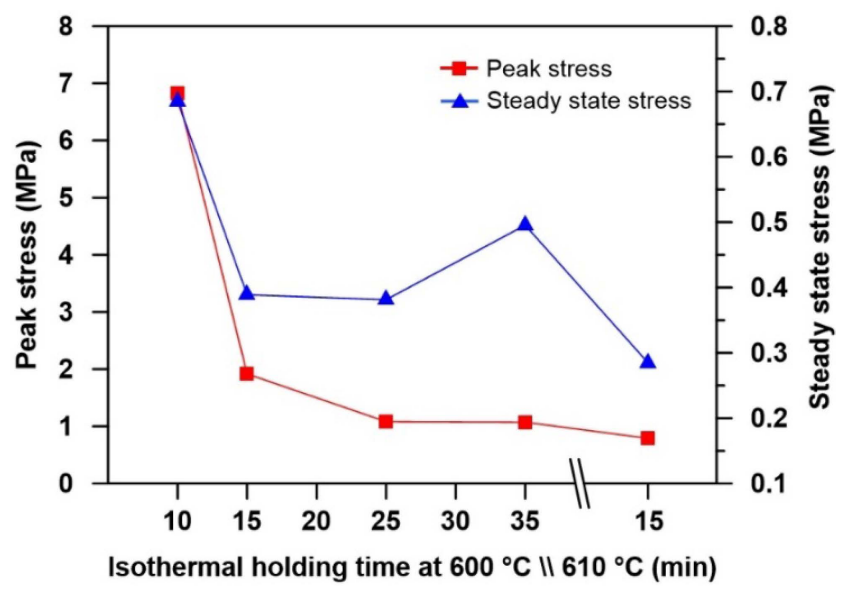

Figure 17. Peak and steady state stresses of the SIMA processed samples with different initial microstructures.

Figure 18e,f shows the microstructure of the center region (region 2 in Figure 18a) of the hot compressed semi-solid samples prepared by heating at $600{ }^{\circ} \mathrm{C}$ for 25 and $35 \mathrm{~min}$, respectively. After compression, no evidence of the plastic deformation of the solid grains was observed in the microstructure of the samples. There was no difference in the microstructure of the center regions and edge regions, which indicated that the solid and the liquid flowed together during the compression. However, it is worth mentioning that the liquid fraction in the edge regions was slightly high, which was due to the liquid phase being squeezed out during the deformation. The microstructural observations also revealed that the solid grains do not experience plastic deformation in the SIMA samples prepared by heating at 600 and $610{ }^{\circ} \mathrm{C}$ for $15 \mathrm{~min}$. According to Chen and Tsao [46], the plastic deformation of solid particles (PDS), sliding between the solid particles (SS), liquid flow (LF), and the flow of liquid incorporating solid particles (FLS) are four dominant mechanisms controlling deformation of alloys in the semi-solid state. The two former mechanisms are active when the solid particles are in contact with each other and the other two mechanisms are dominant when the solid particles are surrounded by the liquid phase. Therefore, it can be deduced that the sample with near equiaxed initial microstructure deform through the mechanism of PDS. In the case of globular initial microstructures, the SS and FLS mechanisms are dominant, however, the effectiveness of the SS mechanism may dwindle and the FLS mechanism is reinforced on prolonging the isothermal holding temperature and time due to the decrease of the interconnection between the solid grains.

The close examination of the hot compressed microstructure of different samples (Figure 18) also reveals that the microstructure of the SIMA processed sample with near equiaxed and elongated initial grains contains a higher amount of porosity, especially in regions 2 and 3, (shown by arrows in Figure 18c,d) compared to the samples with globular microstructure. In the sample with near equiaxed initial microstructure, the low amount of liquid content leads to higher viscosity, which may prevent the homogenous flow of the liquid and solid particles during deformation. Therefore, this sample 
shows a high amount of porosity in the microstructure. In addition, as shown by dotted ovals in Figure 18c, recrystallization occurs in some parts of the center region in the sample with an incomplete spheroidized initial microstructure during hot compression. It is believed that this recrystallization may occur dynamically as a result of higher induced strain in the center regions compared to the edge regions during hot compression.
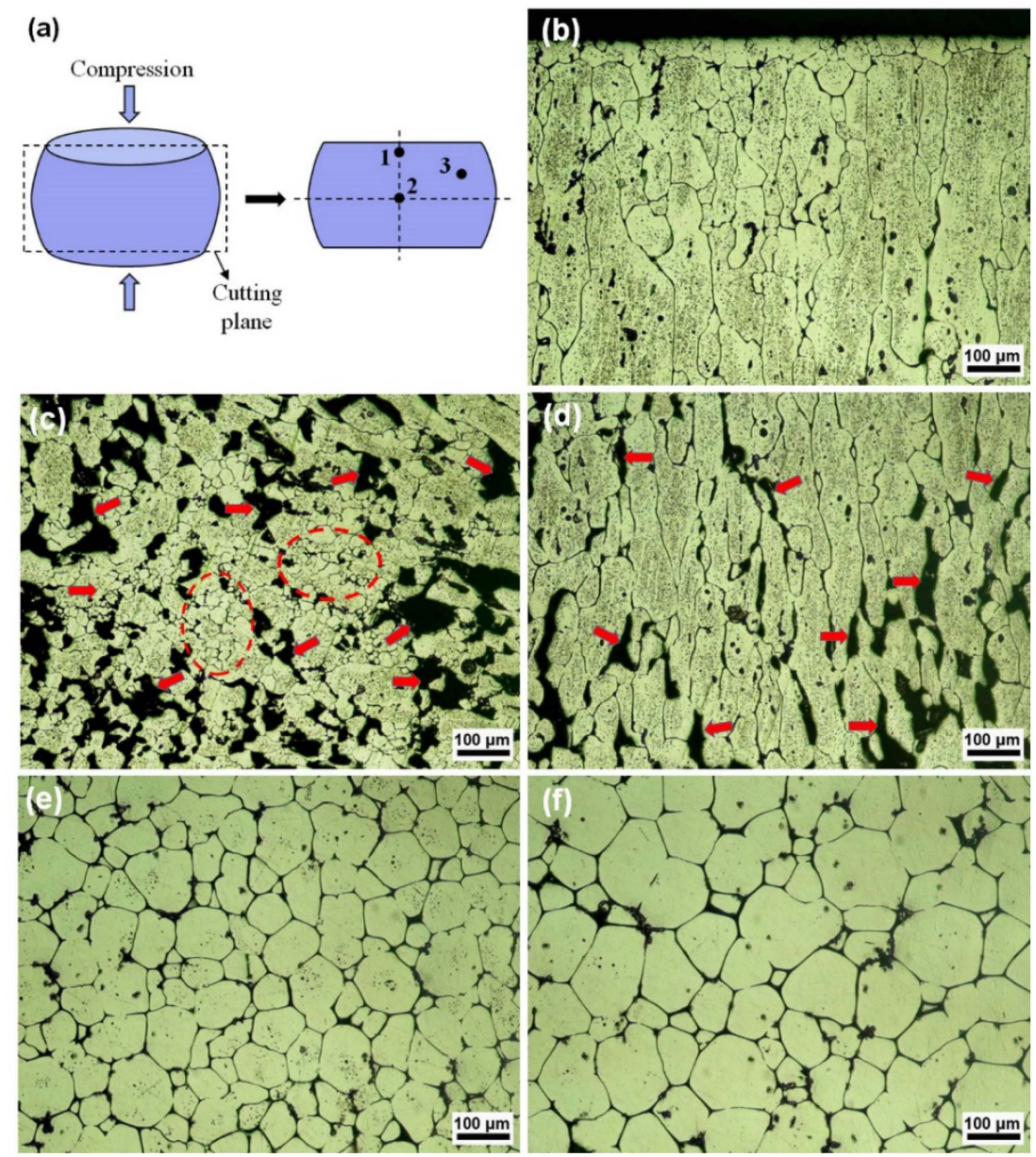

Figure 18. (a) Schematic of a hot compressed SIMA sample showing compression direction; Optical micrographs of (b) region 1; (c) region 2; (d) region 3 of SIMA sample processed at $600{ }^{\circ} \mathrm{C}$ for $10 \mathrm{~min}$; region 2 of SIMA sample processed at $600{ }^{\circ} \mathrm{C}$ for (e) $25 \mathrm{~min}$; (f) $35 \mathrm{~min}$ after hot compression at $600{ }^{\circ} \mathrm{C}$.

\section{Conclusions}

The SIMA process consisting of applying uniaxial compression strain at ambient temperature and subsequent semi-solid treatment in the range of $600-620^{\circ} \mathrm{C}$ for $5-35 \mathrm{~min}$ was investigated. It has been found that using the cold compression process following by heating in the semi-solid range results in some phase evolution that is suitable for obtaining a semi-solid microstructure for subsequent thixoforming. The following results can be drawn from the analysis:

The results showed that the partial remelting kinetics during the SIMA process consist of four steps including recrystallization and structural separation, coarsening of polygonal solid particles, spheroidization of polygonal particles, and coarsening of spherical particles. The growth and coarsening of the solid particles in the SIMA process are controlled by two mechanisms of coalescence (for low liquid fractions) and Ostwald ripening (for high liquid fractions).

The XRD results of the compressed samples heated at $600{ }^{\circ} \mathrm{C}$ for different times showed that $\mathrm{MgZn}_{2}(\eta), \mathrm{Al}_{2} \mathrm{CuMg}(\mathrm{S})$, and $\mathrm{Mg}_{2} \mathrm{Si}$ precipitates are dissolved gradually during isothermal heating 
through the phase transformations of $\alpha-\mathrm{Al}+\eta \rightarrow \mathrm{L}$ and then $\alpha-\mathrm{Al}+\mathrm{S}+\mathrm{Mg}_{2} \mathrm{Si} \rightarrow \mathrm{L}$. However, Fe-rich precipitates aggregate as square particles at grain boundaries due to their higher melting points.

An intense segregation of $\mathrm{Si}$ and $\mathrm{Cu}$ was observed at the grain boundaries in the semi-solid microstructure which results in shifting of the grain boundary composition toward the Al-Si and Al-Cu eutectics. In contrast, a significant depletion of $\mathrm{Mg}$ was observed at the grain boundaries and $\mathrm{Zn}$ distribution showed no appreciable change during isothermal treatment.

Microstructural observations indicated that the isothermal heating temperature range of $600-610^{\circ} \mathrm{C}$ for $25 \mathrm{~min}$ can be considered an optimum condition for the SIMA process. Coarsening kinetics of the solid particles is fairly well correlated to the LSW theory during isothermal heating. Despite the higher liquid fraction of samples heated at $610^{\circ} \mathrm{C}$, the coarsening rate at $610^{\circ} \mathrm{C}$ was lower than $600^{\circ} \mathrm{C}$.

Samples with near equiaxed initial microstructure containing elongated and polygonal solid grains and samples with globular initial microstructure with average grain size of $61 \mu \mathrm{m}$ show the greatest and the lowest flow resistance during the thixoforming process at $600{ }^{\circ} \mathrm{C}$, respectively. The flow resistance decreases on raising the deformation temperature.

Author Contributions: Behzad Binesh performed the experiments and wrote the paper under Mehrdad Aghaie-Khafri's guidance, and contributed to all activities.

Conflicts of Interest: The authors declare no conflict of interest.

\section{References}

1. Kirkwood, D.H.; Suery, M.; Kapranos, P.; Atkinson, H.V. Semi-Solid Processing of Alloys; Springer: London, UK, 2009; pp. 109-112.

2. Flemings, M.C. Behavior of metal alloys in the semisolid state. Metall. Trans. A 1991, 22, 957-981. [CrossRef]

3. Jayaraj, J.; Fleury, E.; Kim, K.-B.; Lee, J.-C. Globulization mechanism of the primary Al of Al-15Cu alloy during slurry preparation for rheoforming. Met. Mater. Int. 2005, 11, 257-262. [CrossRef]

4. Zhang, Q.Q.; Cao, Z.Y.; Zhang, Y.F.; Su, G.H.; Liu, Y.B. Effect of compression ratio on the microstructure evolution of semisolid AZ91D alloy. J. Mater. Process. Technol. 2007, 184, 195-200. [CrossRef]

5. Saklakoglu, N.; Saklakoglu, I.E.; Tanoglu, M.; Oztas, O.; Cubukcuoglu, O. Mechanical properties and microstructural evaluation of AA5013 aluminum alloy treated in the semi-solid state by SIMA process. J. Mater. Process. Technol. 2004, 148, 103-107. [CrossRef]

6. Chen, T.J.; Hao, Y.; Sun, J. Microstructural evolution of previously deformed ZA27 alloy during partial remelting. Mater. Sci. Eng. A 2002, 337, 73-81. [CrossRef]

7. Tzimas, E.; Zavaliangos, A. A comparative characterization of near-equiaxed microstructures as produced by spray casting, magnetohydrodynamic casting and the stress induced melt activated process. Mater. Sci. Eng. A 2000, 289, 217-227. [CrossRef]

8. Lin, H.Q.; Wang, J.G.; Wang, H.Y.; Jiang, Q.C. Effect of predeformation on the globular grains in AZ91D alloy during strain induced melt activation (SIMA) process. J. Alloys Compd. 2007, 431, 141-147. [CrossRef]

9. Kang, B.K.; Hong, C.P.; Choi, B.H.; Jang, Y.S.; Sohn, I. Microstructural evolution in semisolid forging of A356 alloy. Met. Mater. Int. 2015, 21, 153-158. [CrossRef]

10. Young, K.P.; Kyonka, C.P.; Kamado, S. Fine Grained Metal Composition. U.S. Patent 4415374, 30 March 1983.

11. Jiang, J.; Wang, Y.; Atkinson, H.V. Microstructural coarsening of 7005 aluminum alloy semisolid billets with high solid fraction. Mater. Charact. 2014, 90, 52-61. [CrossRef]

12. Yan, G.; Zhao, S.H.; Ma, S.H.; Shou, H. Microstructural evolution of A356.2 alloy prepared by the SIMA process. Mater. Charact. 2012, 69, 45-51. [CrossRef]

13. Jung, H.K.; Seo, P.K.; Kang, C.G. Microstructural characteristics and mechanical properties of hypo-eutectic and hyper-eutectic Al-Si alloys in the semi-solid forming process. J. Mater. Process. Technol. 2001, 113, 568-573. [CrossRef]

14. Curle, U.A.; Govender, G. Semi-solid rheocasting of grain refined aluminum alloy 7075. Trans. Nonferrous Met. Soc. China 2010, 20, s832-s836. [CrossRef]

15. Yong, L.S.; Hwan, L.J.; Seon, L.Y. Characterization of Al 7075 alloys after cold working and heating in the semi-solid temperature range. J. Mater. Process. Technol. 2001, 111, 42-47. [CrossRef] 
16. Chayong, S.; Atkinson, H.V.; Kapranos, P. Thixoforming 7075 aluminum alloys. Mater. Sci. Eng. A 2005, 390, 3-12. [CrossRef]

17. Chayong, S.; Atkinson, H.V.; Kapranos, P. Multistep induction heating regimes for thixoforming 7075 aluminum alloy. Mater. Sci. Technol. 2004, 20, 490-496. [CrossRef]

18. Atkinson, H.V.; Burke, K.; Vaneetveld, G. Recrystallisation in the semi-solid state in 7075 aluminum alloy. Mater. Sci. Eng. A 2008, 490, 266-276. [CrossRef]

19. Vaneetveld, G.; Rassili, A.; Atkinson, H.V. Influence of parameters during induction heating cycle of 7075 aluminum alloys with RAP process. Solid State Phenom. 2008, 141-143, 719-724. [CrossRef]

20. Bolouri, A.; Shahmiri, M.; Kang, C.G. Study on the effects of the compression ratio and mushy zone heating on the thixotropic microstructure of AA 7075 aluminum alloy via SIMA process. J. Alloys Compd. 2011, 509, 402-408. [CrossRef]

21. Mohammadi, H.; Ketabchi, M.; Kalaki, A. Microstructure evolution of semi-solid 7075 aluminum alloy during reheating process. J. Mater. Eng. Perform. 2011, 20, 1256-1263. [CrossRef]

22. Seo, P.K.; Kang, C.G. The Effect of raw material fabrication process on microstructural characteristics in reheating process for semi-solid forming. J. Mater. Process. Technol. 2005, 162-163, 402-409. [CrossRef]

23. Zhang, L.; Liu, Y.B.; Cao, Z.Y.; Zhang, Y.F.; Zhang, Q.Q. Effects of isothermal process parameters on the microstructure of semisolid AZ91D alloy produced by SIMA. J. Mater. Process. Technol. 2009, 209, 792-797. [CrossRef]

24. Doherty, R.D.; Lee, H.-I.; Feest, E.A. Microstructure of stir-cast metals. Mater. Sci. Eng. 1984, 65, 181-189. [CrossRef]

25. Tzimas, E.; Zavaliangos, A. Evolution of near-equiaxed microstructure in the semisolid state. Mater. Sci. Eng. A 2000, 289, 228-240. [CrossRef]

26. Wang, T.; Yin, Z.-M.; Sun, Q. Effect of homogenization treatment on microstructure and hot workability of high strength 7B04 aluminum alloy. Trans. Nonferrous Met. Soc. China 2007, 17, 335-339. [CrossRef]

27. Fan, X.-G.; Jiang, D.-M.; Meng, Q.-C.; Zhang, B.-Y.; Wang, T. Evolution of eutectic structures in Al-Zn-Mg-Cu alloys during heat treatment. Trans. Nonferrous Met. Soc. China 2006, 16, 577-581. [CrossRef]

28. Lim, S.T.; Lee, Y.Y.; Eun, I.S. Microstructural evolution during ingot preheat in 7xxx aluminum alloys for thick semiproduct applications. Mater. Sci. Forum 2006, 519-521, 549-554. [CrossRef]

29. Li, N.-K.; Cui, J.-Z. Microstructural evolution of high strength 7B04 ingot during homogenization treatment. Trans. Nonferrous Met. Soc. China 2008, 18, 769-773. [CrossRef]

30. Jiang, L.-T.; Wu, G.-H.; Yang, W.-S.; Zhao, Y.-G.; Liu, S.-S. Effect of heat treatment on microstructure and dimensional stability of ZL114A aluminum alloy. Trans. Nonferrous Met. Soc. China 2010, 20, 2124-2128. [CrossRef]

31. Boettinger, W.J.; Kattner, U.R.; Moon, K.W.; Perepezko, J.H. DTA and heat-flux DSC measurements of alloy melting and freezing. In Methods for Phase Diagram Determination, 1st ed.; Zhao, J.C., Ed.; Elsevier: Ames, IA, USA, 2007; pp. 194-200.

32. Annavarapu, S.; Doherty, R.D. Inhibited coarsening of solid-liquid microstructures in spray casting at high volume fractions of solid. Acta Metall. Mater. 1995, 43, 3207-3230. [CrossRef]

33. Liu, D.; Atkinson, H.V.; Kapranos, P.; Jones, H. Effect of heat treatment on properties of thixoformed high performance 2014 and 201 aluminum alloys. J. Mater. Sci. 2004, 39, 99-105. [CrossRef]

34. Cavaliere, P.; Cerri, E.; Leo, P. Effect of heat treatments on mechanical properties and fracture behavior of a thixocast A356 aluminum alloy. J. Mater. Sci. 2004, 39, 1653-1658. [CrossRef]

35. Bolouri, A.; Shahmiri, M.; Kang, C.G. Coarsening of equiaxed microstructure in the semisolid state of aluminum 7075 alloy through SIMA processing. J. Mater. Sci. 2012, 47, 3544-3553. [CrossRef]

36. Jiang, H.; Li, M. Microscopic observation of cold-deformed Al-4Cu-Mg alloy samples after semi-solid heat treatments. Mater. Charact. 2005, 54, 451-457. [CrossRef]

37. Shim, S.-Y.; Kim, D.-H.; Chio, S.-H.; Kim, Y.-H.; Bai, H.; Lim, S.-G. The analysis of variance on process parameters affecting the microstructures of semi-solid Al-Zn-Mg alloy billet by cooling plate method. Met. Mater. Int. 2010, 16, 1009-1017. [CrossRef]

38. Baker, H. ASM Handbook, Alloy Phase Diagrams; ASM International: Materials Park, OH, USA, 2004; Volume 3, pp. 295-331.

39. Shackelford, J.F.; Alexander, W. Materials Science and Engineering Handbook, 3rd ed.; CRC Press LLC: Boca Raton, FL, USA, 2001. 
40. Vaneetveld, G.; Rassili, A.; Pierret, J.C.; Beckers, J.L. Conception of tooling adapted to thixoforging of high solid fraction hot-crack-sensitive aluminum alloys. Trans. Nonferrous Met. Soc. China 2010, 20, 1712-1718. [CrossRef]

41. Manson-Whitton, E.D.; Stone, I.C.; Jones, J.R.; Grant, P.S.; Cantor, B. Isothermal grain coarsening of spray formed alloys in the semi-solid state. Acta Mater. 2002, 50, 2517-2535. [CrossRef]

42. Li, P.; Chen, T.; Zhang, S.; Guan, R. Research on semisolid microstructural evolution of 2024 aluminum alloy prepared by powder thixoforming. Metals 2015, 5, 547-564. [CrossRef]

43. De Freitas, E.R.; Ferracini, E., Jr.; Ferrante, M. Microstructure and rheology of an AA2024 aluminum alloy in the semi-solid state, and mechanical properties of a back-extruded part. J. Mater. Process. Technol. 2004, 146, 241-249. [CrossRef]

44. Tzimas, E.; Zavaliangos, A. Mechanical behavior of alloys with equiaxed microstructure in the semisolid state at high solid content. Acta Mater. 1999, 47, 517-528. [CrossRef]

45. Clarke, B. Rheology of coarse settling suspensions. Trans. Inst. Chem. Eng. Chem. Eng. 1967, 45, 251-256.

46. Chen, C.P.; Tsao, C.-Y.A. Semi-solid deformation of non-dendritic structures-phenomenological behavior. Acta Mater. 1997, 45, 1955-1968. [CrossRef]

(C) 2016 by the authors; licensee MDPI, Basel, Switzerland. This article is an open access article distributed under the terms and conditions of the Creative Commons by Attribution (CC-BY) license (http://creativecommons.org/licenses/by/4.0/). 